\title{
Eritía, la isla menor: el suburbium occidental de Gades
}

\author{
Eritía, the minor island: the western suburbium of Gades
}

\begin{abstract}
Macarena Lara Medina, macarena.lara@uca.es, http://orcid.org/0000-0003-2574-7875, Universidad de Cádiz, España Darío Bernal-Casasola, dario.bernal@uca.es, https://orcid.org/0000-0003-1107-5318, Universidad de Cádiz, España
\end{abstract}

\section{Resumen}

Hasta fechas muy recientes, el actual casco histórico de Cádiz ha sido interpretado de manera unidireccional por la investigación arqueológica como espacio intramuros de la ciudad romana. Esta interpretación posiblemente ha estado determinada por varios motivos: por un lado, debido al parcelario sumamente atomizado que añade complejidad a la lectura histórica; y que además dificulta la visión de conjunto de los restos arqueológicos, también derivada de la alteración de la secuencia estratigráfica motivada principalmente por la intensa reocupación del espacio de manera continuada, principalmente desde época romana hasta la actualidad, escenario común que comparten las ciudades históricas. Por otro lado, por desconocimiento de los límites del pomerium y de la estructura de la ciudad romana. Todos estos factores han contribuido al conocimiento parcial de la ciudad antigua, a lo que debemos unir el carácter inédito de numerosos informes, así como de su estructura, de las áreas funcionales y de la dinámica ocupacional.

La revisión, el análisis y la actualización de los datos arqueológicos existentes y su interpretación en conjunto junto a nuestro mejor conocimiento paleotopográfico del archipiélago gaditano han permitido realizar una primera propuesta de la ubicación y estructura de la ciudad romana, así como de la articulación de las áreas extra moenia.

De este modo, con este trabajo se da a conocer, por un lado, la existencia de dos áreas suburbanas de Gades y, por otro, se presenta la configuración y los resultados del análisis de los testimonios arqueológicos de la zona que a partir de ahora proponemos denominar el suburbium occidental de Gades, sito en la llamada isla menor o Eritía (la Erytheia de las fuentes).

\begin{abstract}
Until recently, the current historic center of Cádiz has been interpreted in a unidirectional way by archaeological research as an intramural space of the Roman city. This interpretation may have been determined by several reasons. On the one hand, because of the highly atomised parcels of land that add complexity to the historical reading and also hinder the overall view of the archaeological remains, which also derives from the alteration of the stratigraphic sequence, mainly due to the continued intense reoccupation of the space, mainly from Roman times to the present day, a common scenario shared by the historic cities. On the other hand, due to the lack of knowledge about the pomerium limits and the structure of the roman city. All these factors have contributed to the partial knowledge of the ancient city, its structure, functional areas and occupational dynamics, to which we must add the fact that numerous reports are unpublished.

The review, analysis and update of the existing archaeological data and its interpretation, together with our best paleotopographic knowledge of the Cadiz archipelago, have allowed us to make a first proposal regarding the location and structure of the Roman city, as well as the articulation of the extra moenia areas.

Therefore, this work reveals the existence of two suburban areas in Gades, as well as the configuration and results of the analysis of the archaeological testimonies of what we suggest calling western suburbium of Gades, located in the so called minor island or Eritía (Erytheia in the classical sources).
\end{abstract}

Key words. Gades; small island; suburban area; extra moenia; productive and crafs area; Urbs Iulia Gaditana.

Palabras clave. Gades; isla menor; área suburbana; extra moenia; área productiva y artesanal; Urbs Iulia Gaditana.

Financiación: Este trabajo es resultado y ha sido financiado por el proyecto «La gestión de los residuos sólidos en Gades. Aproximación a la caracterización tipológica de los vertidos y su inserción en el entramado urbano de una ciudad costera» (CEIJ-006) de la Fundación CEiMAR; por el proyecto GARVM III (PID2019-108948RB-I00/ AEI / 10.13039/501100011033) del Gobierno de España/Feder; por el Programa Operativo FEDER 2014-2020 y por la Consejería de Economía, Conocimiento, Empresas y Universidad de la Junta de Andalucía (referencia del proyecto: ARQUEOSTRA, FEDER-UCA18-104415); por el proyecto ARQUEOFISH (P18-FR-1483) del Programa de Ayudas a la I+D+i del Plan Andaluz de Investigación, Desarrollo e Innovación (PAIDI 2020) y por el proyecto GARVMTRANSFER (PDC2021-121356-I00), de la convocatoria de Prueba de Concepto 2021 del Ministerio de Ciencia e Innovación. 


\section{INTRODUCCIÓN}

Tradicionalmente la investigación sobre la zona suburbana de la Cádiz romana se ha centrado principalmente en las áreas de necrópolis. Los estudios realizados al respecto han focalizado su atención en los enterramientos, en el material mueble vinculado a estos contextos funerarios, así como en las estructuras que circundan y pertenecen a éstos (Arévalo, 2010; Corzo, 1989; 1992; Jiménez Cisneros, 1971; Niveau de Villedary, 2009; Niveau de Villedary y Gómez, 2010; Quintero, 1917a; $1917 b$; 1928 como más destacados). Recientemente, se ha abordado esta línea de estudio de forma interdisciplinar y desde diversos puntos de vista, ofreciendo nuevos datos que aportan resultados enriquecedores para la comprensión no sólo del conjunto completo de estas áreas de necrópolis, sino también para la economía, usos, funciones y origen de ciertos objetos como la moneda (Arévalo, 2016). Sin embargo, los esfuerzos centrados en los enterramientos y su contexto no han propiciado el estudio de la ubicación y simbiosis que estos espacios comparten con los centros productores ubicados en el mismo entorno, pues al fin y al cabo se localizan extra moenia, lugares como sabemos no exclusivos de las necrópolis (Vaquerizo, 2010). Esta coyuntura ha velado de una u otra manera la comprensión y estudio íntegro de las áreas suburbanas de la Gades romana, si bien ha constituido un estímulo para el inicio de nuevas perspectivas en la investigación de la topografía y el urbanismo de la ciudad antigua de Cádiz (Fig. 1).

Con todo, esta situación se ve agravada por la existencia de un parcelario muy atomizado que añade complejidad al estudio de los testimonios arqueológicos de manera individual donde la secuencia estratigráfica se ve alterada constantemente por las cíclicas construcciones fruto de la dinámica en este tipo de ciudades (Lara, 2019a). No debemos tampoco olvidar en el caso particular de Cádiz que el carácter insular de la misma condicionó su topografía, mantenido durante toda la época antigua como demuestran los últimos estudios geoarqueológicos (Bernal-Casasola et al., 2020a; 2020b), constriñendo la ajetreada y bulliciosa vida de la ciudad. Hasta la fecha contábamos con una visión parcial de la ciudad antigua y el estudio en conjunto de todos los testimonios arqueológicos quedaba obstaculizado, siendo una necesidad imperiosa que algunos autores reclamaban desde hacía algunos años (Bernal-Casasola y Lara, 2012; Abad y Corzo, 2017) y que recientemente ha sido tenida muy presente en el acercamiento a su problemática urbana (Lara, 2019b).

Una vez traspasado ese obstáculo con los datos actualizados, homogeneizados y analizados de manera conjunta, en la medida de las posibilidades disponibles y con todos los condicionantes derivados de la arqueología preventiva de la cual procede casi toda la información, se pueden plantear cuestiones que hasta la actualidad no habían sido abordadas, como sucede con los suburbia de Gades.

El estudio de las áreas suburbanas de época romana ha sido hasta finales de los años 70 una cuestión pendiente, década en la cual se comenzó a plantear el inicio y el fin de la propia ciudad (Quilici, 1974). Esta línea se consolida en el siglo XXI con autores como E. Champlin y N. Purcell, R. Volpe, X. Lafón o R. Witcher, y grandes obras como la de V. Jolivet (2009) y P. Goodman (2007) que abordan de manera detallada
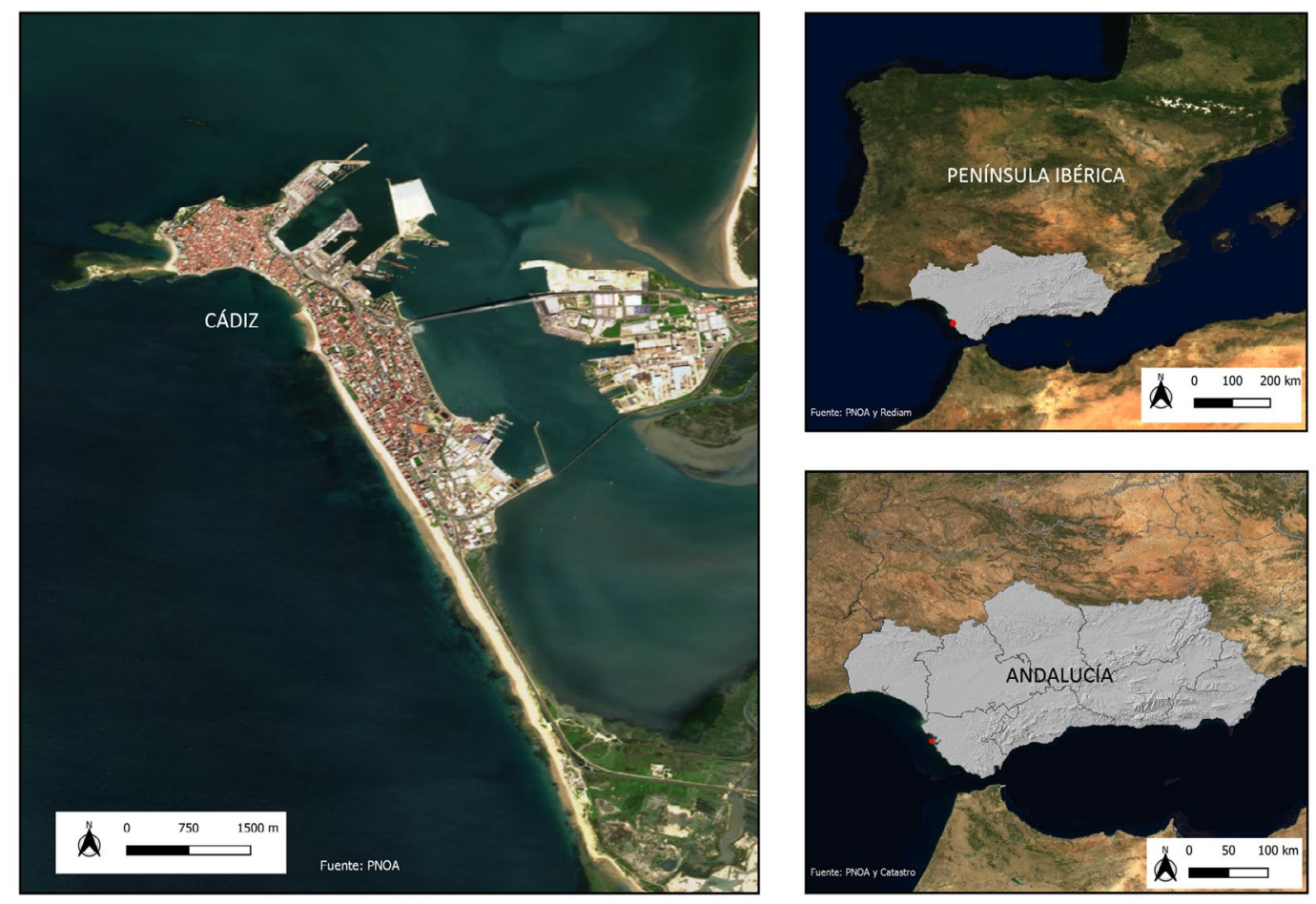

Figura 1: Localización de Cádiz al suroeste de la península ibérica y de la Comunidad Autónoma de Andalucía 
estas cuestiones. En España será P. Fernández Vega (1994) el encargado de plantear la problemática sobre los usos del suelo de las ciudades hispanas en época altoimperial, al tiempo que M. Buzón (2011) aborda de manera magistral la discusión del empleo de conceptos referidos a suburbanum, suburbium, suburbanus y los usos en los textos literarios clásicos. Debemos destacar la última gran aportación de D. Vaquerizo, que aúna y analiza estudios de las áreas suburbanas de las principales ciudades hispanorromanas como Mérida, Carmona, Sevilla y Barcelona (2010).

En las principales ciudades hispanas el estudio de las áreas suburbanas ha permitido conocer el funcionamiento, mecanismo, patrón y motor económico de las mismas. Para ello, el primer factor a tener en cuenta es su delimitación. Estos espacios quedan definidos normalmente por la existencia de un recinto amurallado que separa físicamente dos grandes áreas urbanas, el pomerium y el entorno suburbano, donde la dicotomía es visible pero inseparable en economía y política. En ciudades como Augusta Emerita, Barcino, Tarraco, Corduba, Carthago Nova o, por mencionar las más cercanas, Baelo Claudia y Carteia, la localización parcial de uno o varios tramos de muralla ha permitido delimitar de manera concluyente el pomerium del área periurbana y suburbana que, como espacios dinámicos y cambiantes, añaden complejidad a su caracterización (Garriguet, 2010). Como sabemos aún no se han documentado evidencias arqueológicas de la muralla de Gadir/Gades.

En el caso gaditano que nos ocupa, el registro arqueológico no había permitido hasta la actualidad aportar datos empíricos de las áreas suburbanas, como pasa en casos cercanos como la vecina Baelo Claudia, en la cual se ha definido recientemente el suburbium occidental (Bernal-Casasola et al., 2013). Las problemáticas principales para abordar la identificación y la delimitación de las áreas suburbanas de Gades son las que sintetizamos a continuación: un estudio centrado principalmente en las áreas de necrópolis; un parcelario atomizado; la condición de ciudad histórica que altera considerablemente el registro arqueológico; y la escasez de documentación arqueológica, así como la ausencia de recinto amurallado, aspectos todos ellos que han dificultado esta tarea. En fechas recientes, la tesis doctoral defendida por uno de los firmantes (Macarena Lara Medina) ha permitido determinar la existencia de dos áreas suburbanas, una oriental y otra occidental (Fig. 2), además de la posible ubicación, estructura y entramado viario del pomerium y de sus posibles áreas circundantes (Lara, 2019b), así como la distribución del abastecimiento y evacuación hídrica de la ciudad imperial (Lara, 2018b).

Es por ello que los objetivos principales de este artículo son reflexionar sobre la presencia de dos áreas suburbanas en Gades, activas de manera coetánea, y flanqueando la ciudad en época imperial. Hasta la fecha, la investigación había considerado la existencia de una única área suburbana localizada en el extremo oriental de la ciudad, que correspondería con

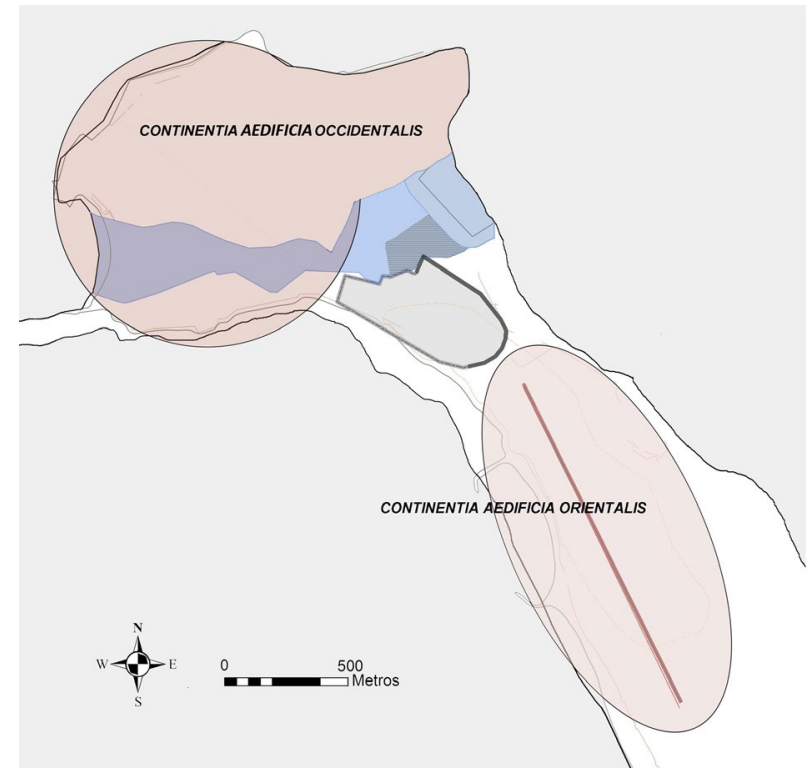

Figura 2: Plano esquemático de Cádiz con la propuesta de distribución y estructura del pomerium y de las dos áreas suburbanas identificadas de Gades (actualizado sobre Lara, 2019b: 92), con el estrecho interinsular (o canal «Bahía-Caleta») abierto tras los estudios más recientes de la Universidad de Cádiz

la isla grande o Cotinusa. En segundo lugar, analizar de manera minuciosa los testimonios arqueológicos existentes en el extremo occidental de la ciudad con el objeto de presentar en las próximas páginas los resultados del análisis en detalle del área suburbana occidental y de los contextos arqueológicos analizados, con datos mayoritariamente inéditos.

\section{LA PALEOTOPOGRAFÍA DE LA ISLAMENOR: UNA CUESTIÓN EN VÍAS DE DESARROLLO}

La historiografía ha aspirado a comprender e interpretar la fisionomía de la ciudad romana, aquella mentada por los autores latinos que tanto alababan en sus textos literarios (Rodríguez Neila, 1980). Ahora bien, para llegar a comprender la estructura y conformación urbana de Gades, como sucede en cualquier estudio de estas características, es imprescindible reflexionar sobre el marco geomorfológico y topográfico donde se inserta tanto a escala micro como macroespacial.

El enclave donde se ubica actualmente el yacimiento de Gades presenta un substrato geológico compuesto principalmente por materiales arcilloso-margosos que constituyen la base sedimentaria que aflora en superficie, así como por las arenas amarillas con laminaciones cruzadas y fosilíferas y por los conglomerados cementados, con ostras y pectínidos, la popularmente llamada «piedra ostionera» (Esteban, 2020). Tras un relleno y fosilización con el depósito de arenas rojas aluviales, con cantos de cuarcita y cuarzo, se produce el paso a un régimen continental (Domínguez, 2008: 120-121): en ellas se documentan abundantes restos arqueológicos, sobre todo de época fenicio-púnica. 


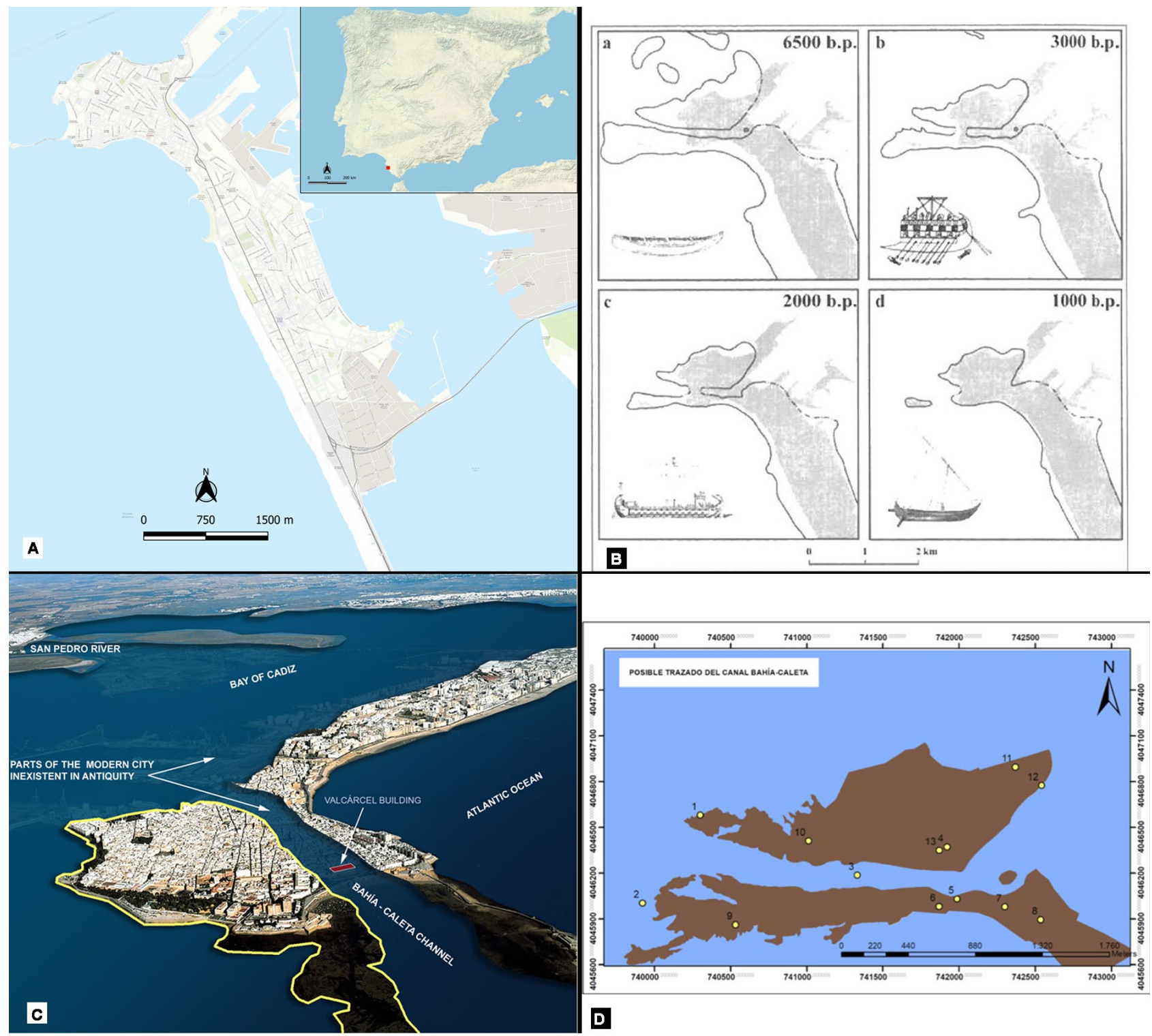

Figura 3: Topografía actual de Cádiz (A), y propuesta tradicional (B.- Arteaga et al., 2001: fig. 4) y actual del canal «Bahía-Caleta» abierto tras los trabajos en el edificio Valcárcel (C.- Bernal-Casasola et al., 2020a; D.- Gómez Muñoz, 2018: 134, fig. 2), con la isla Eritía contorneada en amarillo

Actualmente Cádiz es un apéndice de tierra unido al continente gracias a una estrecha lengua de tierra (Fig. 3: A). En la Antigüedad, sin embargo, no estaba conformada por una única isla y de ello nos informan los autores clásicos. Estrabón hacía mención a la existencia de dos islas, la pequeña, donde se ubicaba la ciudad vieja; y la ciudad «Nueva» construida por Balbo localizada en el extremo occidental de la isla grande (Geogr., III, V, 5). Estas islas a las que se refiere Estrabón y que actualmente no son visibles en el entramado de la ciudad, se corresponden con Erytheia (Eritía, la isla pequeña) y la isla de Cotinoussa (Cotinusa, la grande ${ }^{1}$ ),

1. Sobre la problemática filológica de los términos latinos y griegos alusivos a ambas islas y de cómo a veces Gadir era reemplazado por el primero de ellos, Eritía o la isla roja, ambas separadas por un estrecho paso de agua, según informa el autor; datos que confirman tanto Plinio (Historia Natural, IV, 22, 36) como Pomponio Mela (Corografia, III, 46).

Los investigadores contemporáneos han realizado una aproximación a la topografía de la ciudad de Gades atraídos por los datos que los autores clásicos aportaron

remitimos al trabajo de Fernández Camacho, 2012: passim. A pesar del peso historiográfico del nombre Erytheia, una de las conocidas Hespérides, que ha inspirado incluso el título de la revista científica de la Asociación Cultural Hispano-Helénica - Erytheia. Revista de Estudios Bizantinos y Neogriegos (http://www.hispanohelenica.org/publicaciones-achh/revistaerytheia/), consideramos que conviene normalizar el empleo de estos términos en castellano, dinámica aún no producida en la investigación histórico-arqueológica actual. 
en sus obras, pero cuya descripción no se llegaba a asemejar con la fisionomía que en la actualidad presentaba la ciudad. En los años veinte del siglo pasado algunos geólogos de manera muy acertada comenzaron a centrar sus estudios en la influencia que ejercía el río Guadalete en la bahía (Gavala y Laborde, 1924: 228-229; 1973), pero realmente fue F. Ponce Cordones quien abrió una nueva línea de investigación en los años setenta, aportando luz a la paleotopografía y configuración de la ciudad antigua a través de su sagaz propuesta del posible brazo de mar que accedería por la actual calle San Juan de Dios, hacia la Plaza de las Flores, Plaza de la Libertad y continuaría hacia la calle Sagasta hasta llegar a La Caleta (Ponce Cordones, 1985: 106). Esta hipótesis supuso un hito para el estudio arqueológico de la ciudad, tanto es así que fue bautizado como el «canal de Ponce» $\mathrm{y}$, con posterioridad, «canal bahía Caleta».

La existencia de este canal impulsó a principios del siglo XXI el Proyecto Antípolis, encabezado por el profesor O. Arteaga, con el objeto de conocer de primera mano las dinámicas sufridas en la línea de costa de la bahía de Cádiz. Para ello, en la capital gaditana se realizaron en total 19 perforaciones geoarqueológicas distribuidas por el actual casco histórico por donde se pensaba que transcurría el canal (una síntesis en detalle en Arteaga y Schulz, 2008). Esta novedosa técnica confirmó la existencia de un paleocanal, el cual se hallaría completamente abierto hasta inicios de época fenicia arcaica, momentos a partir de los cuales se habría iniciado su paulatino cegamiento, especialmente en la zona del actual barrio de la Viña (Arteaga et al., 2001: 376; Arteaga y Roos, 2002: 28), sobre todo en el extremo occidental de la ciudad (Fig. 3: B). Recientemente, nuevos estudios realizados en el edificio Valcárcel por un grupo interdisciplinar encabezado por el Grupo de Investigación HUM-440 de la Universidad de Cádiz y de la Université de Strasbourg/ CNRS, han confirmado, por un lado, la existencia de un fondeadero de época fenicia y romana a más de 25 $\mathrm{m}$ de profundidad bajo la rasante actual, con una sedimentación de una incalculable riqueza arqueológica; $y$, por otro, que el canal estuvo totalmente abierto y operativo durante la Protohistoria y la Antigüedad Clásica (Bernal-Casasola et al., 2020a; 2020b; Salomon et al., 2020) como ilustramos en la figura 3: C. Es decir, que durante todo el período romano existieron dos islas, siendo ese el paisaje que vieron los Cornelios Balbos y los gaditanos hasta finales de la Antigüedad Clásica.

Por su parte, los testimonios arqueológicos confirman esta nueva propuesta paleotopográfica (Lara, 2018a). Evidencian la existencia de una ocupación continuada en el entorno inmediato situado en la Torre Tavira y en los alrededores, así como en la zona oeste de la isla desde época fenicia (de manera puntual) y púnica de manera asidua hasta la Antigüedad Tardía. Al sur del canal, los hallazgos han permitido documentar una ocupación puntual en el extremo suroriental del actual barrio de La Viña. Sin embargo, en las proximidades de la plaza de San Juan de Dios hacia la zona portuaria no se ha documentado aún material arqueológico que permita confirmar la ocupación antrópica. Quizá, las áreas no ocupadas por el canal serían lugares de playa, a veces inundables y no susceptibles de ser habitadas de manera estable. Los restos arqueológicos y los datos geomorfológicos han permitido elaborar una propuesta del trazado y de las paleo-orillas del canal Bahía-Caleta, actualizando así el conocido plano de F. Ponce (1985) y J. R. Ramírez (1982). Consideramos que el canal presentaba una anchura máxima de $450 \mathrm{~m}$ por su extremo norte y una mínima de 100/150 m en su zona más estrecha, que coincidiría con la zona de Puerto Chico. Asimismo, si observamos el trazado del canal, éste discurriría por debajo de las curvas de nivel 5 y/o 6 m s.n.m. (Lara, 2018a).

De la paleolínea de costa se ha publicado recientemente una nueva propuesta, con el canal o estrecho interinsular abierto y con áreas de gran anchura y longitud. Este dato es determinante para la comprensión de la morfología y estructura de la ciudad romana y para determinar las áreas funcionales de la misma.

En definitiva, la investigación en las últimas décadas y el uso de técnicas propias de otras disciplinas aplicadas en arqueología han permitido arrojar luz en diversas cuestiones que se encontraban en un estado embrionario. Gracias a estos datos, se ha podido contrastar la información que proporcionaban las fuentes literarias acerca de la complexión de la Gades romana. La isla menor o Eritía se localizaba al norte del canal «Bahía-Caleta», con unas dimensiones aproximadas de 800 m norte-sur y 1300 m este-oeste, que coinciden aproximadamente con las propuestas recientemente (Gracia, 2019). Morfológicamente se presentaba como un gran promontorio en la zona correspondiente con la actual Torre Tavira, a una cota estimada de 20/21 m s.n.m. Desde este altiplano descendería una gran ladera con pendiente por su lado sur-sureste para desembocar en el canal o estrecho interinsular (Fig. 4). Desde otro punto elevado, situado en el extremo occidental a 13 m s.n.m., correspondiente con la zona del parque Genovés, habría una pendiente suave y progresiva hasta alcanzar las orillas del canal en la orilla norte de La Caleta. El resto de extremos conformarían acantilados con algunas posibles playas de difícil acceso mientras que el margen oriental posiblemente estaría caracterizado por playas y dunas. Según F. J. Gracia, la parte elevada a 9 m s.n.m., en dirección oeste/suroeste-este/ noreste conformaría el llamado «Bloque Erytheia» (Gracia, 2019: 130).

Con todo, aún quedan pendientes numerosas cuestiones paleotopográficas por abordar y determinar, entre otras, la morfología real, cotas, límites y trazado del canal, aspectos que deberán ser tratados en detalle en los próximos años. No olvidemos tampoco que desgraciadamente, a estos efectos, la ciudad de Cádiz está forrada por las fortificaciones de época moderna y contemporánea (Calderón Quijano, 1976; Ruiz y Jiménez, 2019) (Calderón Quijano, 1976), lo cual dificulta enormemente el conocimiento en detalle de las orillas de la 


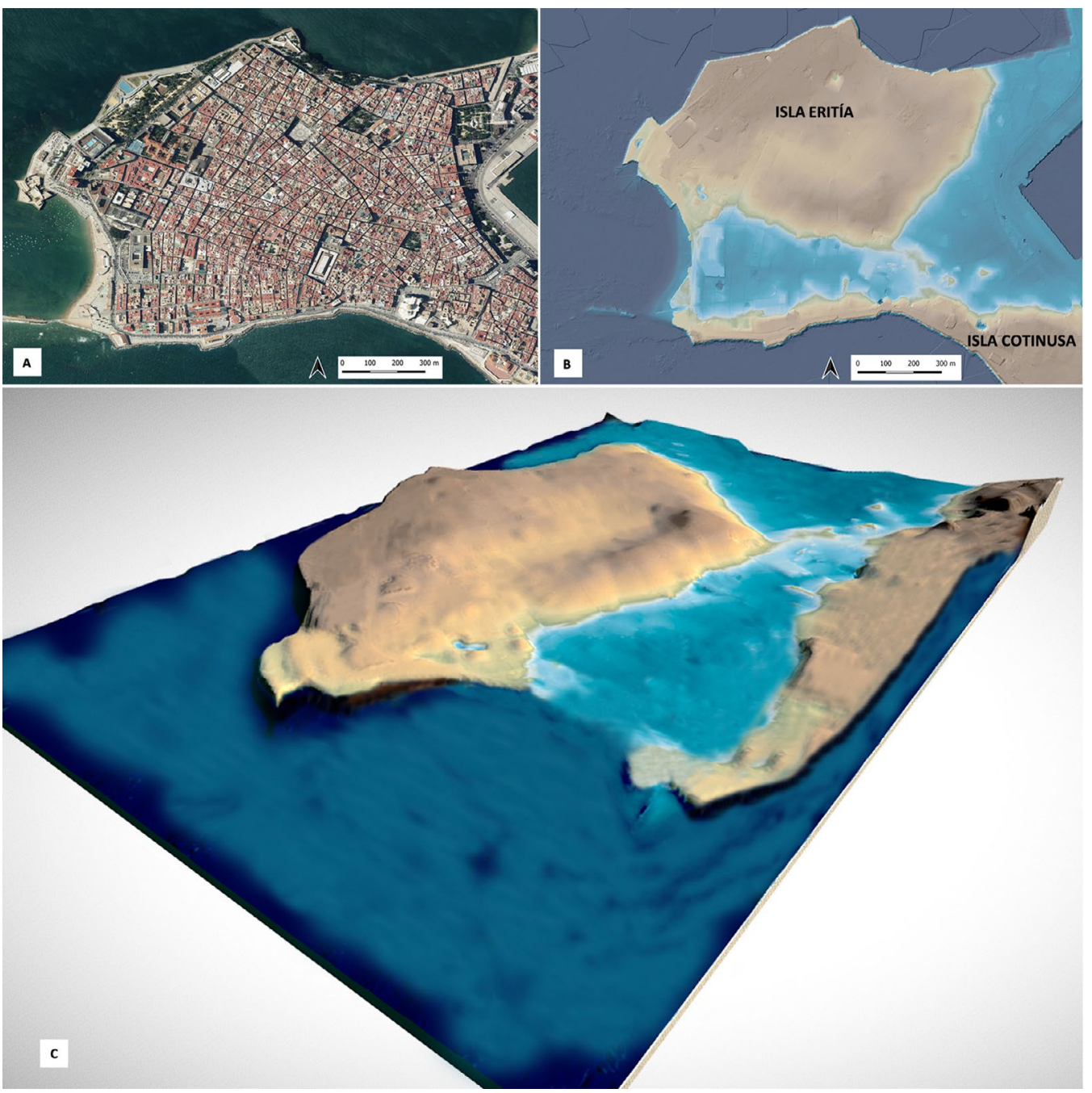

Figura 4: Vista general de la zona objeto de estudio en la actualidad a través del PNOA (A). Vista cenital del procesado del MDT (B). Modelo 3D del área suburbana occidental de Gades a partir de la elaboración del modelo digital del terreno realizado por MLM. Postprocesado a partir de los datos LIDAR obtenidos en el Instituto Geográfico Nacional (C)

isla menor y, al mismo tiempo de la paleotopografía de su interfaz marítimo-terrestre.

En definitiva, la topografía de la isla menor podría reunir las condicionas más favorables para establecer el principal centro productivo y artesanal extra moenia de la ciudad de Gades en época altoimperial, tanto por cuestiones topográficas con las playas y diques que la harían accesible a través de medios fluvio-marítimos como por el terreno propicio para establecer estructuras para la explotación agrícola y ganadera. Por otro lado, las características edafológicas de Cádiz y, en concreto, de la isla menor son similares a las existentes en otros lugares de la provincia con un elevado índice de fertilidad que propicia el rendimiento de cultivos comunes (Manúel-Vez y García Vargas, 1992). Según el mapa de tipologías de suelos de Andalucía, Cádiz está compuesta por suelos del tipo fluvisol formados a partir de materiales aluviales recientes aportados por los ríos y de alto interés agrícola. Estos suelos rojos característicos son favorables para olivares y viñedos, así como para áreas de sembraduras o calmas y algunos regadíos
(Ortega, 1975-1976). En definitiva, una tierra propicia y con gran potencial para la agricultura, como detallaremos en los siguientes apartados.

\section{ERITÍA: DINÁMICAS DE OCUPACIÓN EN LA ANTIGÜEDAD}

El término Eritía puede adscribirse a varios orígenes y significados, y como su propio nombre indica tiene implícito el «color rojo». En este sentido, se ha planteado la vinculación de este término con Gadir/Eritía debido a la procedencia de sus habitantes y fundadores, del Mar Eritreo o Rojo haciendo referencia a su etimología, siendo indiscutible la identificación de los fenicios con este color, asimilación que se mantuvo hasta la Antigüedad Tardía (Fernández Camacho, 2012: 91). Más allá de las cuestiones etimológicas, la identificación de Eritía con el color rojo ha sido relacionada con aspectos mitológicos: como es el caso de las reses de Gerión y sus «vacas rojas», ubicándose 


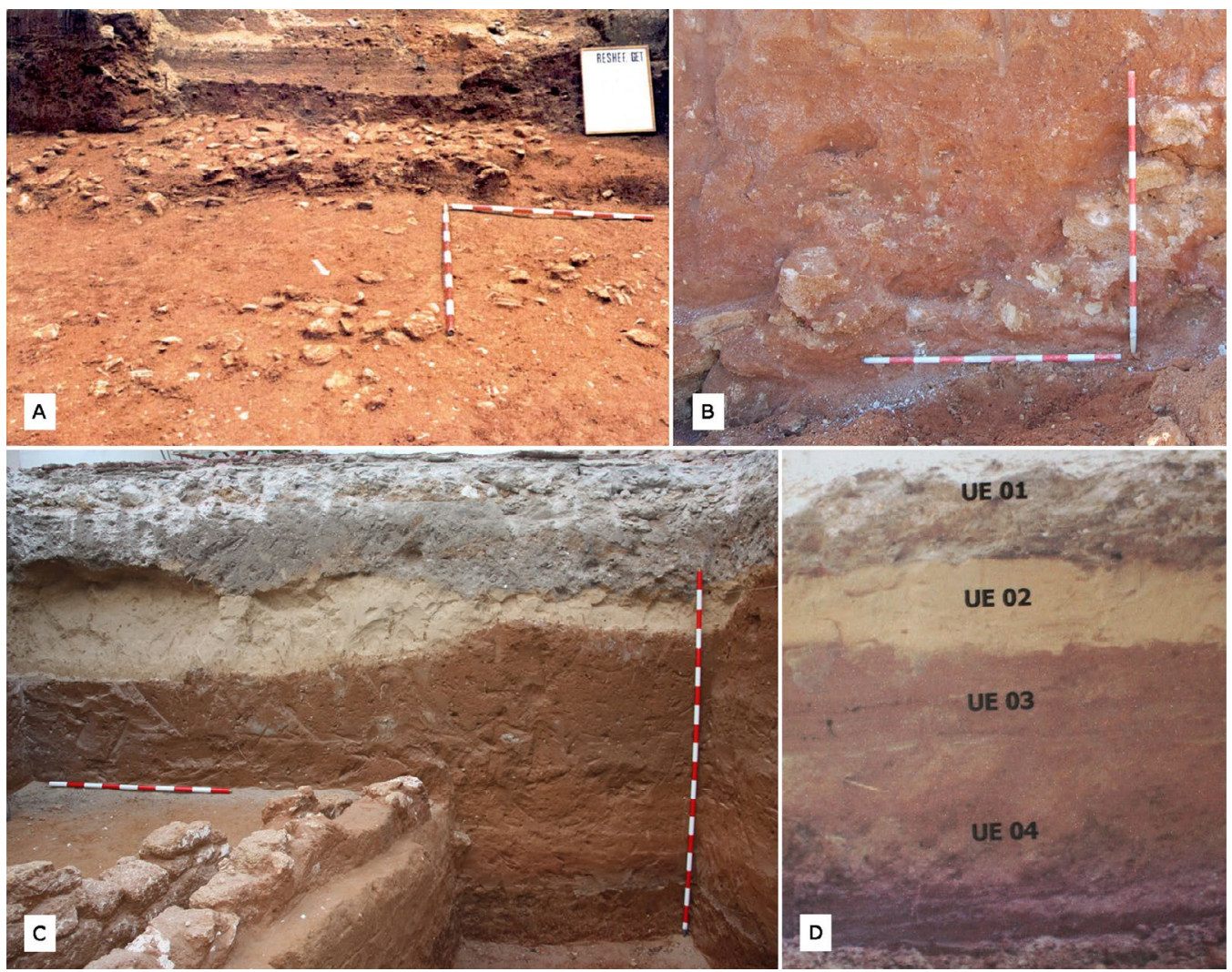

Figura 5: Niveles de ocupación de coloración roja en la calle Gómez Ulla, 24 (A.- Pineda, 2001: fig. 18), Santa Bárbara (B.- Pineda, 2012), Colegio Mayor Universitario (C.- Lara y Bernal-Casasola, 2019: fig. 10) y Avda. Dr. Gómez Ulla, 20 (D.- Sánchez Aragón, 2003: fig. 2)

tradicionalmente el desarrollo del mito de Gerión en la isla menor o Eritía, como aludía Estrabón en su pasaje, afirmación que atribuía a Ferécides (Fernández Camacho, 2012: 90). Algunos autores se refieren a Eritía en el contexto del mito de Gerión y la imagen del extremo occidente como un lugar ambiguo, que representa tanto el lado infernal con los rebaños de Hades como a la vez un lugar celestial identificado con Helios (Burkert, 1977: 277; Ballabriga, 1986: 50-51).

Más allá de estos aspectos mitológicos, el término 'Epú $\theta \varepsilon \imath \alpha^{\prime}$ o Eritía refleja muy bien el lugar al que identifica geográficamente, el suelo donde se ubica, que es de color carmesí. La secuencia geológica que se observa en las excavaciones arqueológicas así lo corroboran: unos niveles de color rojo intenso que se asocian normalmente a los niveles más antiguos de la ocupación como se puede observar en la figura 5, propicios para el establecimiento de cultivos y ganadería, como se ha mencionado en el apartado anterior, que se alternan, en el extremo norte de Cádiz, con pequeños cuerpos dunares que han sido conformados por el viento de levante y por las citadas arcillas rojas (Gracia, 2019: 132).

Para comprender la evolución del extremo occidental de Cádiz y la estructura que obtendrá en época imperial, debemos conocer previamente su organización en época republicana o tardopúnica. Los cambios urbanísticos que protagonizó la ciudad de Gades paulatinamente vinieron marcados por un momento histórico de intensas mutaciones políticas y económicas. Gracias al estudio de multitud de actividades arqueológicas en más de 70 solares de Cádiz que han ofrecido datos arqueológicos positivos desde los años ochenta hasta $2016^{2}$, parece que durante todo el período romano la ciudad estuvo conformada por dos áreas suburbanas, si bien en época republicana la pequeña ciudad intramuros quizá compartiría espacio con el área suburbana occidental, la isla pequeña.

\subsection{LA ISLA MENOR EN ÉPOCA TARDORREPUBLICANA}

El panorama existente en las primeras décadas de romanidad es bien distinto al que se presenta en época imperial, principalmente por cuestiones políticas y administrativas que se ven reflejadas en la estructuración del territorio así como por la herencia urbanística fenicio-púnica (Gener et al., 2014), que condicionó el devenir urbano de la misma desde la firma del conocido foedus del 206 a. C. La dinámica ocupacional que se observa en la isla menor durante este período

2. Un análisis en detalle de los testimonios arqueológicos en Lara, 2019b. Los datos procedentes de los informes de las intervenciones arqueológicas se pueden consultar en el recurso electrónico de la misma monografía https://publicaciones.uca. es/wp-content/uploads/2021/11/Anexo_recurso-electronico_ Urbs_Iulia_Gaditana.pdf 
atestigua la existencia de un área suburbana centrada en actividades productivas y con algunos enterramientos concentrados, a diferencia de Cotinusa que conformaría el primer núcleo activo de producción ubicado a la altura de los actuales Cuarteles de Varela y de la plaza Asdrúbal, manteniendo los focos activos primigenios que comenzaron en torno al $\mathrm{s}$. V a. C. Conforme avanza el tiempo, durante el traspaso y cambio de régimen político y administrativo de los territorios anexionados a Roma, se observan ciertos cambios urbanísticos, pues el extremo occidental de la isla pequeña de Cádiz parece que es ocupado por enclaves de carácter eminentemente productivo, y puntualmente como área funeraria (Fig. 8).

La dificultad del estudio de la ciudad romana en época republicana radica en varios factores. Por un lado, la heterogeneidad, escasez y deficiente estado de conservación de los vestigios arqueológicos y, por otro, la carencia de un estudio de detalle integral de los contextos arqueológicos disponibles. Otro problema metodológico que hemos advertido es la dificultad de precisión a la hora de datar hallazgos en estos momentos de los ss. II y I a. C., ya que el estudio del mobiliario de las excavaciones no está publicado y, por ello, las atribuciones suelen ser genéricas.

Los testimonios arqueológicos, aun siendo exiguos, han permitido establecer un primer planteamiento morfológico de la ciudad ubicada en la margen norte del canal, de planta irregular y de reducidas dimensiones: se localizaría en las proximidades de la Torre Tavira como parecen evidenciar los restos hallados en la calle Marqués del Real Tesoro, 13 (Blanco, 2002; fig. 6: B) y en el Cine Cómico (Gener, Navarro y Pajuelo, 2010; fig. 6: A). En este promontorio se situaría la ciudad, con continuidad desde época fenicia (Gener et al., 2014), cuya extensión proponemos de unas 8 hectáreas aproximadamente. Los datos que hemos considerado para establecer el límite de la zona intramuros han sido los restos estructurales, de funcionalidad polivalente, documentados en la calle Ancha, 29 y en la calle Cánovas del Castillo, 38 (Córdoba y Ruiz Mata, 2005) asociados a vertederos y necrópolis (Fig. 7). A falta de un estudio exhaustivo, estimamos que el área de necrópolis principal se situaría al otro lado del canal, desde el barrio de Santa María hasta la actual calle Trille. Otros autores recientemente han planteado algunas cuestiones en este sentido para época púnica, considerando ambos sectores, la isla pequeña y la isla grande, como espacios eminentemente destinados a las áreas de necrópolis y un pequeño núcleo poblacional en la isla pequeña (Niveau de Villedary, 2015).

Con todo, en la isla pequeña se observan varias concentraciones de enterramientos en torno al Hospital Real (Lavado, 1998) y al Teatro Andalucía (Cobos, Muñoz y Perdigones, 1997; Macías, 2009), además de dos enterramientos aislados en la calle Vea Murgía, 24 (Jurado, 2001) y El Olivillo (Bernal-Casasola y Vargas, 2019: 297), éstos del s. I a. C. El primer núcleo localizado en el Hospital Real Militar estaba compuesto por 10 enterramientos en total, ubicados sobre un nivel dunar y aislados, sin una organización establecida, excepto tres de ellos, que se documentaron en conjunto y cuya cronología era coetánea (Lavado, 1998). El otro núcleo se halló bajo el antiguo Teatro de Andalucía, compuesto por 12 inhumaciones asociadas a un nivel dunar, datadas cronológicamente en el s. II a. C. (Macías, 2009). Como casos aislados, debemos mencionar el posible enterramiento en la calle Vea Murguía, 24 del s. I a. C.
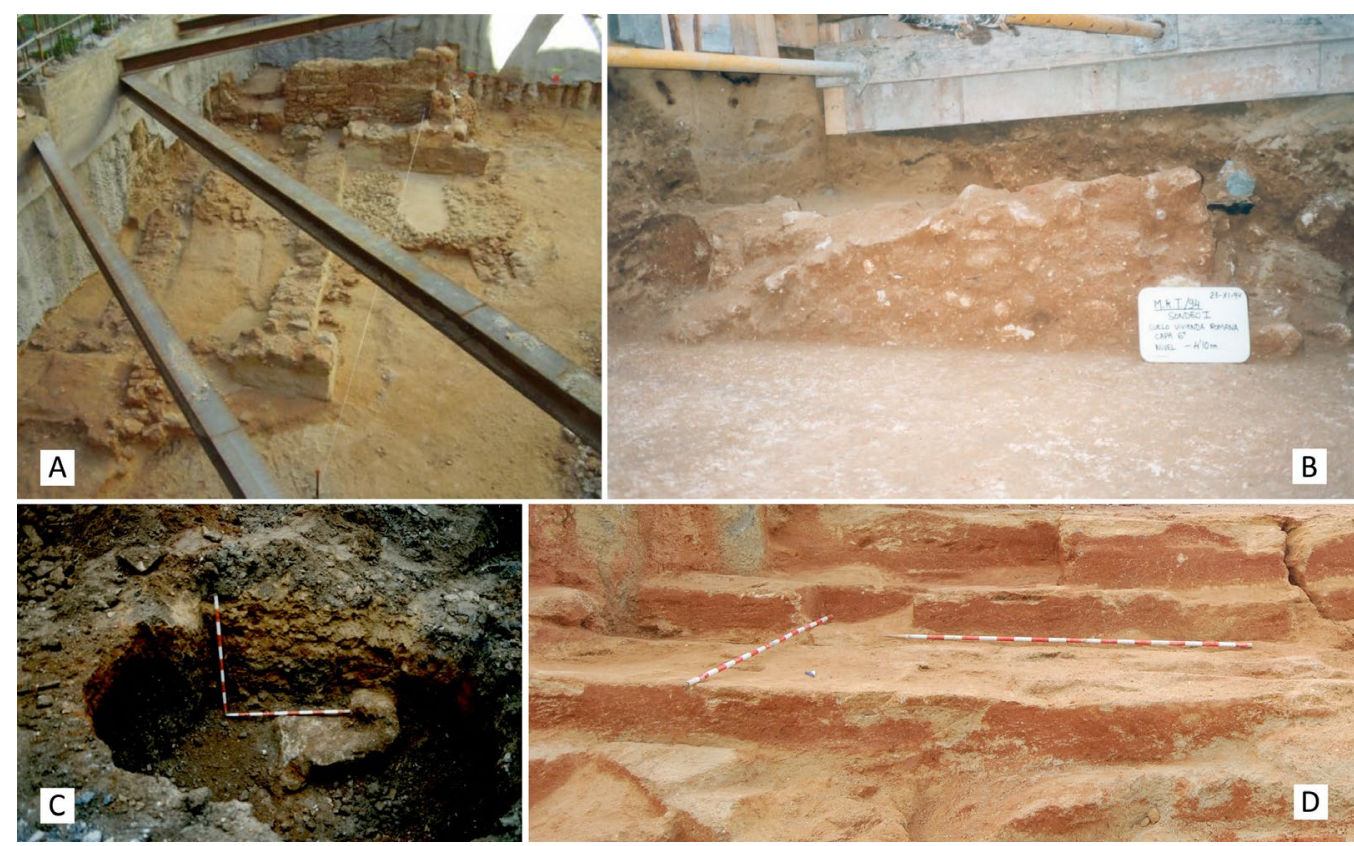

Figura 6: Testimonios arqueológicos documentados en el Cine Cómico (A.- Gener et al., 2010: fig. 82); restos murarios de la calle Marqués del Real Tesoro, 13 (B.- cortesía de F. J. Blanco); niveles de desechos de la calle Pericón de Cádiz, 10 (C.- Blanes, 1997 : foto 12) y uno de los frentes de cantera de Santa Bárbara (D.- Pineda, 2012) 


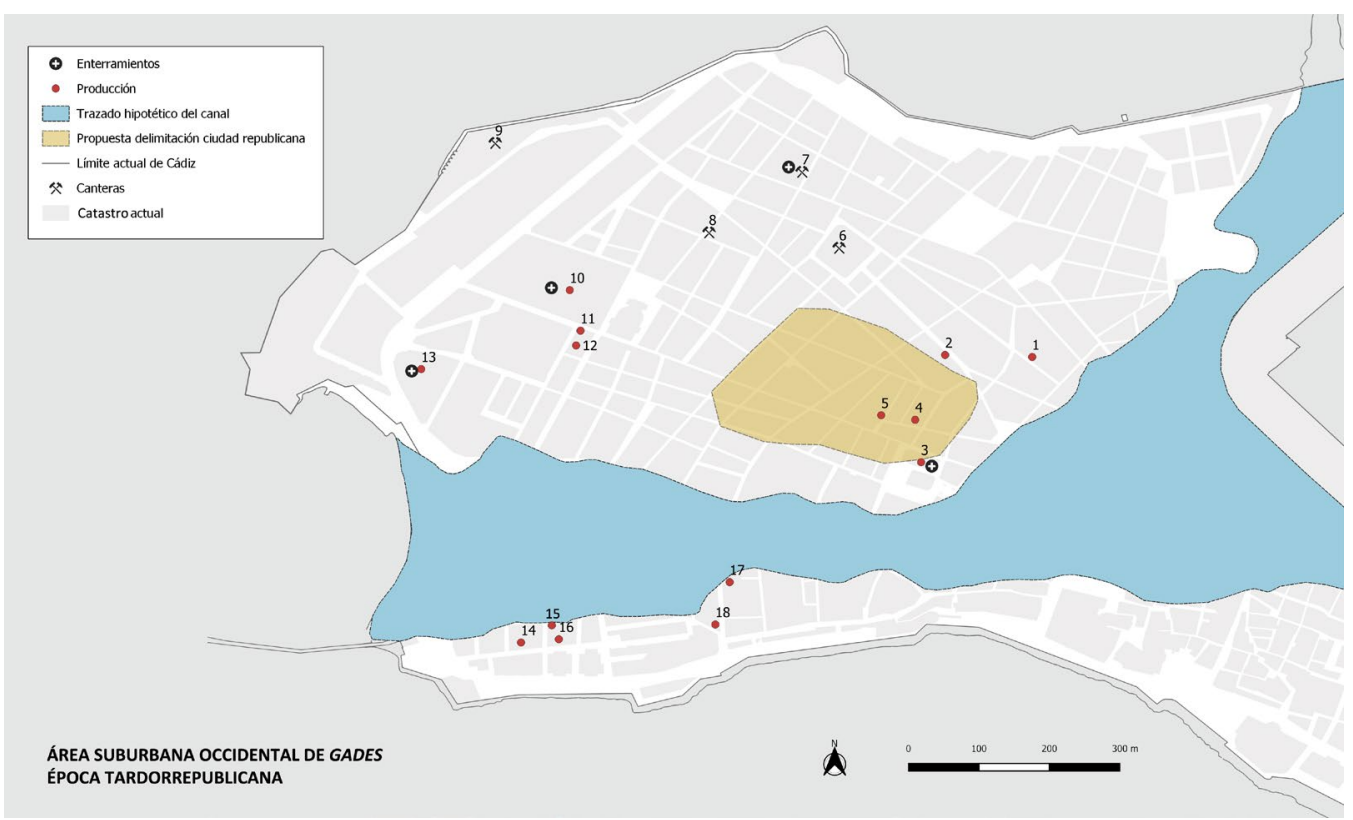

Figura 7: Enclaves con secuencia de época republicana/tardorrepublicana y propuesta de localización y delimitación de la ciudad tardorrepublicana (referencias en figura 9)

(Jurado, 2001) y el documentado en El Olivillo de época tardorrepublicana: una infante inhumada en el interior de una sítula crateriforme en un contexto de vertido, no funerario, posiblemente por ello una tumba «ilegal» (Bernal-Casasola y Vargas, 2019: 297-298). En síntesis, los datos permiten definir una ocupación funeraria en diversos núcleos bien localizados y algunos enterramientos puntuales, siendo la isla menor un lugar de necrópolis secundaria y menor en relación a la isla grande o Cotinusa, quizá manteniendo la tradición de época precedente como verifica el enterramiento arcaico del s. VIII a. C. de la calle Hércules, 12 (Sáez y Belizón, 2014).

Las escasas áreas de producción conocidas se asocian principalmente a vertidos, canteras y espacios no identificados funcionalmente. En primer lugar, resultan de mucho interés los vertidos hallados en este área en época republicana o tardorrepublicana asociados a materiales constructivos de cierta entidad, con potentes niveles de ripios, restos pictóricos y elementos ornamentales como los hallados en la calle Venezuela, 3 y 9 (Blanco, 2004), calle Pericón de Cádiz, 10 (Fig. 6: C), El Olivillo y Santa Bárbara (Fig. 6: D) y otros solares como la calle Chile, 2-4. Indirectamente parecen ilustrar una actividad edilicia de entidad en estos momentos, como atestiguan las evidencias arqueológicas halladas en el actual barrio del Pópulo y Santa María de Cádiz, siendo el ejemplo más representativo el teatro romano. En este mismo contexto deberíamos situar las actividades de cantería que se han documentado en este sector, bien representadas sobre todo por las intervenciones en el Baluarte de Santa Bárbara (Pineda, 2012), en la plaza de San Antonio (Perdigones, 1988), en la calle Vea Murgía, 24 (Jurado, 2001) y en la calle Ceballos, 1-5 (Córdoba, 2005) con frentes de cantera de ostionera bien definidos y con el uso de un sistema de explotación propio del período romano; si bien tenemos constancia de estas prácticas de explotación del substrato de biocalcarenitas en época púnica y tardopúnica como evidencian las numerosas tumbas en cista ampliamente documentadas en Cádiz, la estructura paramental recientemente descubierta en la Cueva del Pájaro Azul y los sillares de gran porte hallados en la Colegio Mayor Universitario, junto a otras evidencias anteriores al s. II a. C. Probablemente debamos asociar estos frentes de cantería al momento de construcción de la ciudad que se estaba erigiendo en el extremo occidental de la isla grande en el s. I a. C. No sería una idea descabellada pues la necesidad de material para construir la nueva ciudad romana sería elevada - un análisis e interpretación en profundidad en M. Lara (s. f.)-. Esta dinámica será la habitual llevada a cabo durante el proceso de romanización en un buen número de ciudades hispanas (Chic, 1997: 223), conformando terrazas artificiales a través de fosas y vertidos, y adaptando el longevo urbanismo insular de tradición fenicio-púnica

Intervenciones área suburbana occidental de Gades

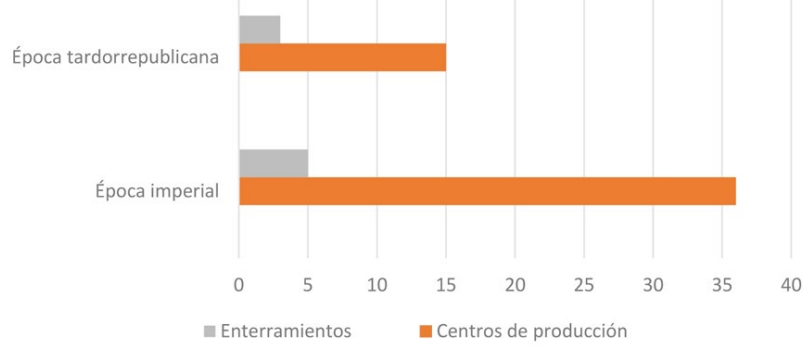

Figura 8: Representación gráfica de los enclaves del área suburbana occidental organizados por épocas y por funcionalidad 
a las necesidades de la Neapolis promovida por Balbo el Menor.

Un buen ejemplo es el de los niveles basales del Testaccio haliéutico de El Olivillo, con vertidos mixtos, compuestos por escombros de materiales de construcción (piedra ostionera muy fragmentada, placas de opus signinum y sillarejo), que alternan con objetos utilitarios, cerámicos (ánforicos principalmente) y de naturaleza variada (Bernal-Casasola y Vargas, 2019: 294-296; Bernal-Casasola et al., 2019). Entre estos materiales destacan los restos de pintura mural, ejemplares que son relevantes debido a que constituyen las primeras evidencias del I estilo pompeyano documentadas en la Ulterior (Fernández et al., 2019). Cabe destacar la tipología de los pavimentos de opus signinum hallados en estos niveles, compuestos por inclusiones de conchas machacadas en el mortero, con motivos florales teselados en blanco y negro (Pascual, 2019). En líneas generales son niveles tardorrepublicanos (75-40/50 a. C.) procedentes de demoliciones de edificios públicos o privados que denotan el importante cambio urbanístico acontecido en estas fechas como hemos observado en otros espacios de la ciudad.

Se puede considerar la existencia de una etapa de transición entre la ciudad tardopúnica y la ciudad imperial, pues se aprecia con claridad la continuidad en ciertas áreas de la ciudad como algunos autores apuntaron acertadamente hace varios años (Niveau de Villedary, 2007), pero a su vez se constatan cambios urbanísticos que se van haciendo más notables conforme avanza el s. I a. C., intensificados aparentemente durante la segunda mitad de la misma centuria, cuando la provincia Ulterior ofrecía una situación idónea, con un gran potencial económico (Chic, 2017). Cambios que también parecen percibirse en la estructuración del territorio, con traspasos de ubicación de determinadas áreas funcionales, al igual que ocurrirá en época imperial; no obstante, la huella de la ciudad de Gadir seguirá siendo palpable como se ha advertido en otros muchos aspectos como por ejemplo en las emisiones de su taller monetal (Arévalo, 2011-2012); en aspectos urbanísticos y edilicios esta impronta también es tangible, tanto por la continuidad de la ubicación de la ciudad como por las técnicas constructivas, de las cuales prevalecen algunas como es el caso del opus africanum, la disposición de la sillería a soga y tizón en las jambas, o la tipología de elementos estructurales, como es el caso de las cisternas a bagnarola (Lara, 2018b). Una dinámica bien conocida en muchas ciudades mediterráneas de raigambre púnica inmersas en un drástico proceso urbanístico pero con múltiples rescoldos de la cultura a la que pertenecieron (Belvedere, 1997; Bendala, 20002001: 419).

Queda patente pues, aunque con una reducida visibilidad arqueológica aún, la continuidad de los orígenes urbanísticos de la ciudad romana, al menos hasta época cesariana, momento en el que César concedió la ciudadanía como premio a sus aliados más fieles (Ferreiro, 2008: 317). A partir de entonces, y especialmente desde el cambio de Era, asistimos a la construcción de manera generalizada de espacios destinados a actividades económicas en la llamada «isla pequeña», que se

\begin{tabular}{|c|c|c|c|c|}
\hline \multicolumn{5}{|c|}{ SOLARES CON SECUENCIA DE ÉPOCA REPUBLICANA/TARDORREPUBLICANA } \\
\hline N. ${ }^{\circ}$ & Ubicación & Necrópolis & Producción & Actividad \\
\hline 1 & C/ Cánovas del Castillo, 38 & & $\mathrm{X}$ & Vertido \\
\hline 2 & C/ Ancha, 29 & & $\mathrm{X}$ & Vertido \\
\hline 3 & C/ Barrié, Teatro Andalucía & $\mathrm{X}$ & $\mathrm{X}$ & Enterramiento/fogatas \\
\hline 4 & C/ San Miguel, Cine Cómico & & Doméstico & Estructuras y pavimentos \\
\hline 5 & C/ Marqués del Real Tesoro, 13 & & Doméstico & Estructuras y pavimentos \\
\hline 6 & Plaza San Antonio & & $\mathrm{X}$ & Vertidos y cantera \\
\hline 7 & C/ Vea Murgía, 24 & $\mathrm{X}$ & & Enterramiento dudoso \\
\hline 8 & C/ Ceballos, 13 & & $\mathrm{X}$ & Cantera \\
\hline 9 & Santa Bárbara & & $\mathrm{X}$ & Vertidos y cantera \\
\hline 10 & Hospital Real Militar & $\mathrm{X}$ & $\mathrm{X}$ & Enterramientos/piletas \\
\hline 11 & C/ Benito Pérez Galdós esquina $\mathrm{C} /$ Chile & & $\mathrm{X}$ & Indeterminado \\
\hline 12 & C/ Chile, 2-4 esquina C/ San Rafael, 5 & & $\mathrm{X}$ & Estructuras artesanales/piletas \\
\hline 13 & El Olivillo & $\mathrm{X}$ & $\mathrm{X}$ & Enterramiento y vertidos \\
\hline 14 & C/ Venezuela, 9 & & $\mathrm{X}$ & Vertidos \\
\hline 15 & $\mathrm{C} /$ Venezuela, 3 & & $\mathrm{X}$ & Vertidos \\
\hline 16 & C/ Pericón de Cádiz, 10 & & $\mathrm{X}$ & Vertido \\
\hline 17 & C/ Sagasta, 96-98 & & $\mathrm{X}$ & Estructuras, almacén \\
\hline 18 & C/ Sagasta, 105 & & $\mathrm{X}$ & $\begin{array}{l}\text { Estructuras artesanales/piletas/ } \\
\text { indeterminada }\end{array}$ \\
\hline
\end{tabular}

Figura 9: Síntesis de los principales testimonios arqueológicos de época republicana y tardorrepublicana 
intensifican exponencialmente respecto a momentos precedentes (Fig. 9). Lamentablemente, en la actualidad no conocemos con suficiente detalle la trama urbana de la ciudad de época fenicia, púnica y tardopúnica para poder abordar un análisis comparativo en detalle con la ciudad romana: esta es una de las líneas que habrá que desarrollar en el futuro.

\subsection{LA PROFUNDA TRANSFORMACIÓN EN ÉPOCA AUGUS- TEA Y SU CONTINUIDAD HASTA ÉPOCA ANTONINA/PRIMO SEVERIANA}

La segunda mitad del s. I a. C. viene marcada por intensos cambios políticos, sociales y económicos, los cuales repercutieron en la dinámica urbana y territorial, habiéndose definido como una época de «experimentación» en la cual se forjaron muchos indicadores que vemos bien definidos más tarde, a partir de época julioclaudia, como sucede con la roturación de su ager en la bahía de Cádiz y con la intensificación de la actividad alfarera y conservera (García Vargas et al., 2019). Los datos arqueológicos documentados al respecto corroboran una intensidad ocupacional en todos los sentidos a partir del mandato del Princeps (Fig. 10). Estos testimonios disímiles, analizados de manera detallada y contrastados en conjunto, permiten confrontar la trama urbana de la ciudad de época republicana con la de época altoimperial, cuyo resultado es la apreciación de cambios sustanciales que se ven reflejados en determinadas zonas de ocupación, principalmente en el área suburbana occidental.
Los restos arqueológicos hallados en este sector de Eritía han sido interpretados como espacios eminentemente de carácter productivo y artesanal que conviven de nuevo, aunque de manera anecdótica, con algunos enterramientos aislados (Fig. 11). Estos enterramientos minoritarios, se corresponden con inhumaciones individuales totalmente aisladas, como es el caso de los enterramientos hallados en el solar del Parking de Tenis (Sánchez Aragón, 2003), en Santa Bárbara (Pineda, 2012), en la calle San José, 27 (Alarcón, 1996) y en el n. ${ }^{\circ} 29$ de la calle Ancha (Sibón, 2003), todos con una cronología coetánea (ss. I y II d. C.). Por otro lado, destacamos algunos conjuntos de sepulturas, como las documentadas en la calle Vea Murguía esquina calle Cervantes (Lavado, 2002) y las aparecidas en la plaza de las Viudas (Herrero, 2005), ambos conjuntos de dudosa cronología como advierten sus excavadores, con unas fechas que abarcan desde el s. I d. C hasta el s. III d. C. Debemos tomar estos datos con cautela pues el panorama en Cádiz a partir del s. III d. C. será bien distinto, no estando exenta de dichos cambios también la isla de Eritía.

Por su parte, los enclaves de origen productivo y artesanal conforman casi el $90 \%$ del total de los hallazgos conocidos, el 70\% circa de los cuales se instalan en época imperial o en torno al cambio de Era (Fig. 10). Tres son las cetariae o centros de producción pesquero-conservera documentadas en este sector de la ciudad: el Teatro Andalucía, La Caleta y el Cine Cómico (Expósito, 2007). Las dos primeras presentan las mismas características modulares de este tipo de construcciones, con patio central y deambulatorio,

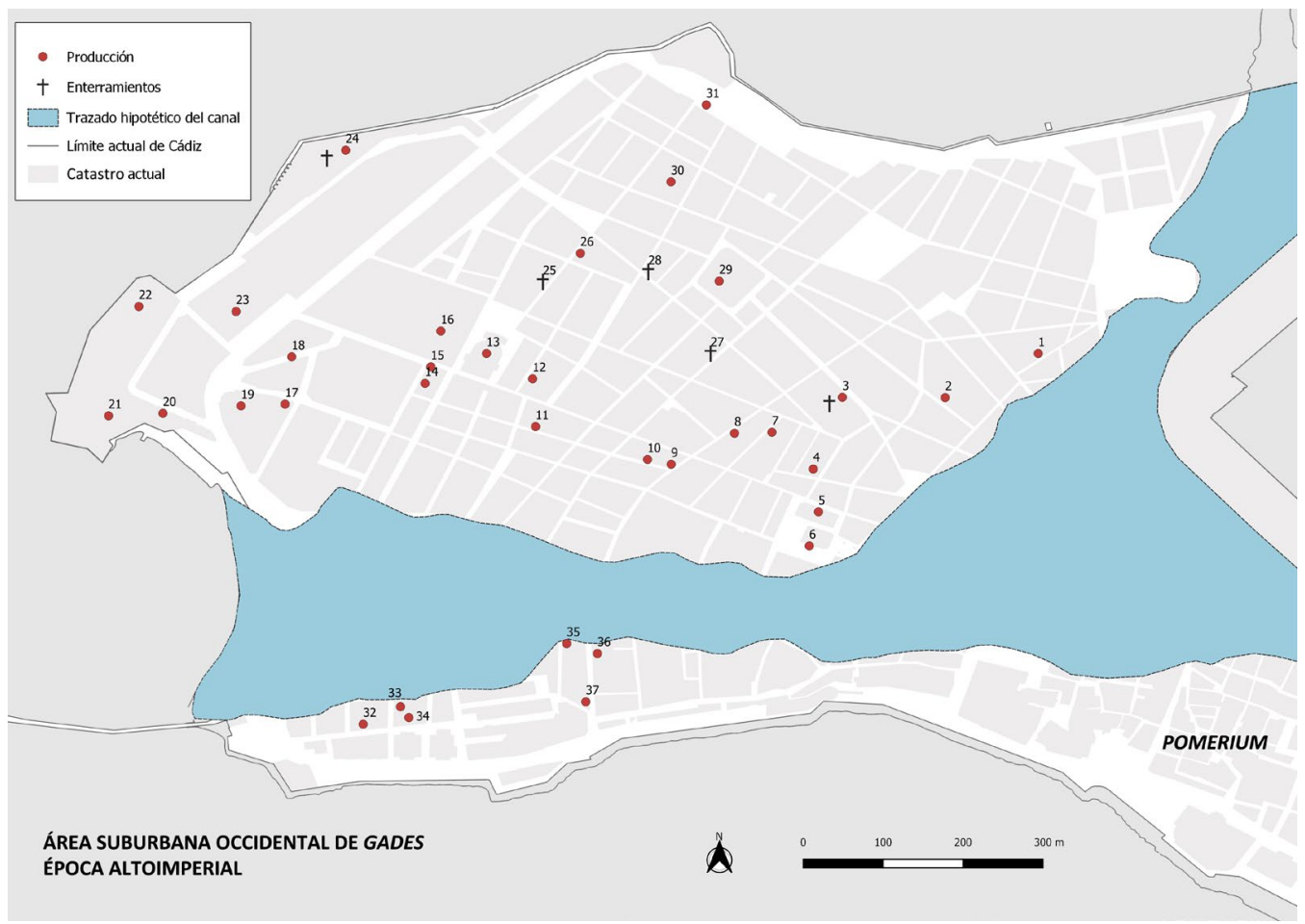

Figura 10: Plano con el área suburbana occidental con la dispersión de las principales evidencias arqueológicas de época altoimperial (referencias en figura 11) 
conjunto de balsas, área de despiece y procesado de los recursos piscícolas. La cetaria emplazada en el Cine Cómico cuenta con un patio central de algo más de $160 \mathrm{~m}^{2}$ : su excepcional estado de conservación ha permitido documentar una gran cisterna con una canalización metálica que abastecía a la misma (Gener, Navarro y Pajuelo, 2010), como en la cercana factoría del Teatro Andalucía (Cobos, Muñoz y Perdigones, 1997; Expósito, 2007), a diferencia de la que se ubica en La Caleta, que presenta un escaso estado de conservación, pero que ha podido ser interpretada como tal gracias al hallazgo de los principales ámbitos que caracterizan a este tipo de edificios (Perdigones, 1989; recientemente Expósito, 2021). Llama la atención la escasez de enclaves destinados al procesado de recursos piscícolas en un lugar que por diversos indicadores se considera el paradigma del procesado y la exportación y comercio de estos productos.

Ocho son los enclaves de dudosa interpretación como instalaciones funcionalmente destinadas al procesado y envasado de los productos piscícolas. El Castillo de Santa Catalina fue interpretado como factoría de salazón, siendo actualmente aceptada su relación con la industria conservera gracias al hallazgo de una pileta, parcialmente excavada (Expósito, 2007: 138; 2021: 113-116). En la calle Gregorio Marañón se documentó un espacio productivo que ha sido interpretado como factoría por sus propios excavadores y por algunos investigadores (Perdigones y Muñoz, 1991; Blanco, 1991; Muñoz, de Frutos y Berriatúa, 1996); otros, sin embargo, se mantienen escépticos al respecto como E. García Vargas (1998), opinión que nosotros compartimos, ya que la longitud de la pileta aparecida y su carácter aislado son singularidades no propias de las piletas de las cetariae. Los otros enclaves de dudosa adscripción funcional (Campo de las Balas, Hotel Atlántico, calle Felipe Abarzuza, Punta de San Felipe, y calle Enrique Calvo) se deben mantener en cuarentena, puesto que es evidente la falta de datos para reafirmar su funcionalidad como espacios de procesado piscícola, sin descartar su posible vinculación total o parcial a otras actividades pesquero-conserveras.

Como parte integrante de los sistemas de explotación, comercio, transporte y la vida diaria se hallan las actividades alfareras. En Gades la instalación de estos complejos alfareros se desarrolló principalmente por toda la costa de la bahía gaditana (Bernal-Casasola, 2008; Ferreiro, 2008), no sólo para facilitar la obtención de los recursos y la necesidad espacial, sino también por la peligrosidad, la contaminación y el ruido que generaba esta actividad, que determinó en época romana su ubicación, regulada por ley, en los cinturones suburbiales de las ciudades romanas. Buen ejemplo de ello es la lex ursonensis, de época cesariana, a través de la cual se prohíbe la instalación de figlinae y tegularia en el interior de la ciudad, aunque parece que concierne sólo a la fabricación de tejas, con multas para los infractores (Tsiolis, 1997: 119-120). Como ha sido indicado en numerosas ocasiones, el hecho de que en la legislación municipal romana se especifique expresamente que las figlinae deberían estar fuera del pomerium es porque en épocas anteriores, al menos parcialmente, debían estar dentro.

En la isla menor de Cádiz se ha podido confirmar hasta la fecha la existencia de un único taller alfarero con horno. De esta piroestructura, localizada en la calle Solano, 3, se ha conservado su planta completa, circular, con un diámetro mayor de $2,50 \mathrm{~m}$ y la mitad inferior íntegra, con la cámara de combustión, parte de la parrilla y el praefurnium. La figlina de la calle Solano habría comenzado a funcionar a mediados del s. I d. C. como indica su contexto material, y se centraba en la manufactura de ánforas salazoneras de la familia de las Dr. 7/11, además de cerámica común de diversa tipología-cuencos, jarras de cuellos estriados y trilobulados, coladores, opérculos, cuencos de base estriada, jarras de cuerpo globular y fondo plano con pie anular, askoi rematados en pitorro y con boca troncocónica y filtro interior, jarras de pasta gris- (Bernal-Casasola, Díaz y Lavado, 2008).

Lamentablemente, es la única evidencia directa documentada relacionada con las actividades alfareras, si bien datos indirectos indican otras posibles localizaciones de alfares; buen ejemplo de ello son los testares y la identificación de cerámicas con defectos de cocción, como ilustra el vertido hallado recientemente en el solar contiguo al del horno de la calle Solano, en la calle Sacramento, 38, actualmente en fase de estudio (Díaz et al., 2021). Los datos aportados por el registro arqueológico en época altoimperial advierten indicadores indirectos de actividad alfarera en un radio de $300 \mathrm{~m}$, posiblemente distribuida en varios focos. El vertido sito en la calle Sagasta, 28 es el más próximo a la piroestructura mencionada (Fig. 12: A). Esta escombrera presenta indicadores de diversas actividades artesanales (Bernal-Casasola et al., 2014) y se localizó a apenas $115 \mathrm{~m}$ del horno de la calle Solano en línea recta, con una secuencia estratigráfica continua desde época tiberiana hasta principios del s. II d. C., aparentemente con su mayor apogeo en época de Claudio (Blanco y Alarcón, 1996). Debemos llamar la atención sobre la existencia de materiales cerámicos hallados con defecto de cocción, como ánforas salazoneras (Dr. 7/11) sobrecocidas y vitrificadas, así como barniz rojo tipo Peñaflor y cerámicas comunes, hecho que aporta información acerca de las actividades alfareras que se realizan en las proximidades. A $35 \mathrm{~m}$ de este solar, se documentó el segundo de los vertidos, localizado en la calle Rosario Cepeda, 2-8. Como ocurre en el citado vertido de la calle Sagasta, su composición es heterogénea con materiales de diversa naturaleza alternando las capas de cenizas con arcillas rojas. El contexto material hallado corresponde con fragmentos anfóricos y cerámica común (tapaderas, jarras, cuencos, biberones y ollas), vajilla fina (vasos de paredes finas, TS itálica y gálica) y elementos constructivos, además de ictiofaunas arqueológicas: nos interesan especialmente los diversos defectos de cocción 


\begin{tabular}{|c|c|c|c|c|}
\hline \multicolumn{5}{|c|}{ SOLARES CON SECUENCIA ALTOIMPERIAL } \\
\hline N. ${ }^{\circ}$ & Ubicación & Necrópolis & Producción & Actividad \\
\hline 1 & C/ General Luque, 4 & & $\mathrm{X}$ & Estructuras/pavimentos/indeterminado \\
\hline 2 & $\begin{array}{l}\text { C/ Cánovas del Castillo, } \\
38\end{array}$ & & $\mathrm{X}$ & Vertido \\
\hline 3 & C/ Ancha, 29 & $\mathrm{X}$ & $\mathrm{X}$ & Enterramiento/vertido \\
\hline 4 & $\begin{array}{l}\text { C/ San Miguel, Cine } \\
\text { Cómico }\end{array}$ & & $\mathrm{X}$ & Estructuras artesanales/piletas/haliéutico \\
\hline 5 & $\begin{array}{l}\text { C/ Barrié, Teatro } \\
\text { Andalucía }\end{array}$ & & $\mathrm{X}$ & Piletas contexto haliéutico \\
\hline 6 & Plaza de Abastos & & $\mathrm{X}$ & Estructuras/indeterminado \\
\hline 7 & C/ Rosario Cepeda, 2-8 & & $\mathrm{X}$ & Vertidos/alfarería/haliéuticos \\
\hline 8 & C/ Sagasta, 28 & & $\mathrm{X}$ & Vertidos/alfarería/haliéuticos \\
\hline 9 & C/ Sacramento & & $\mathrm{X}$ & Vertidos \\
\hline 10 & C/ Solano, 3 & & $\mathrm{X}$ & Horno \\
\hline 11 & C/ Solano, $17-21$ & & $\mathrm{X}$ & Vertidos \\
\hline 12 & C/ Soledad, 15 & & $\mathrm{X}$ & Vertidos \\
\hline 13 & Plaza Fragela & & $\mathrm{X}$ & Estructuras y vertidos/indeterminado \\
\hline 14 & $\begin{array}{l}\text { C/ Chile, 2-4 esquina C/ } \\
\text { San Rafael, } 5\end{array}$ & & $\mathrm{X}$ & Estructuras artesanales/piletas/¿vitivinícola? \\
\hline 15 & $\begin{array}{l}\text { C/ Benito Pérez Galdós } \\
\text { esquina } \mathrm{C} / \text { Chile }\end{array}$ & & $\mathrm{X}$ & Pavimento/indeterminado \\
\hline 16 & Hospital Real Militar & & $\mathrm{X}$ & Estructuras artesanales/piletas/indeterminado \\
\hline 17 & C/ Gregorio Marañón & & $\mathrm{X}$ & $\begin{array}{l}\text { Vertidos/estructuras artesanales/¿haliéutico?/¿ } \\
\text { tinctoria? }\end{array}$ \\
\hline 18 & C/ Felipe Abarzuza & & $\mathrm{X}$ & ¿Estructuras haliéuticas? \\
\hline 19 & El Olivillo & & $\mathrm{X}$ & Vertidos haliéuticos/alfarería \\
\hline 20 & La Caleta & & $\mathrm{X}$ & $\begin{array}{l}\text { Estructuras artesanales/piletas/haliéutico/ } \\
\text { factoría }\end{array}$ \\
\hline 21 & Santa Catalina & & $\mathrm{X}$ & Estructuras/pileta \\
\hline 22 & Campo de las Balas & & $\mathrm{X}$ & ¿Estructuras haliéuticas? \\
\hline 23 & Hotel Atlántico & & $\mathrm{X}$ & ¿Estructuras haliéuticas/vertidos? \\
\hline 24 & Santa Bárbara & $\mathrm{X}$ & $\mathrm{X}$ & Enterramiento/cantería/vertidos \\
\hline 25 & C/ Ceballos, 13 & $\mathrm{X}$ & & Enterramiento \\
\hline 26 & $\begin{array}{l}\text { C/ Ceballos, } 1-5 \text { esquina } \\
\text { C/ Navas, } 13\end{array}$ & & $\mathrm{X}$ & Cantera \\
\hline 27 & C/ San José, 27 & $\mathrm{X}$ & $\mathrm{X}$ & Vertidos/enterramiento \\
\hline 28 & $\begin{array}{l}\text { C/ Vea Murgía, } 1 \text { esquina } \\
\text { C/ Cervantes }\end{array}$ & $\mathrm{X}$ & & Enterramientos \\
\hline 29 & Plaza San Antonio & & $\mathrm{X}$ & Estructuras artesanales/¿villa? \\
\hline 30 & C/ Vea Murgía, 24 & & $\mathrm{X}$ & Cantera \\
\hline 31 & Alameda & & Doméstico/Producción & Indeterminado \\
\hline 32 & C/ Venezuela, 9 & & $\mathrm{X}$ & Vertidos \\
\hline 33 & C/ Pericón de Cádiz, 10 & & $\mathrm{X}$ & Vertidos \\
\hline 34 & C/ Venezuela, 3 & & $\mathrm{X}$ & Vertidos \\
\hline 35 & $\begin{array}{l}\text { C/ Portería de } \\
\text { Capuchinos, } 8\end{array}$ & & $\mathrm{X}$ & Estructuras/pavimentos/indeterminado \\
\hline 36 & C/ Sagasta, 96-98 & & $\mathrm{X}$ & Estructuras y pavimentos/indeterminado \\
\hline 37 & C/ Sagasta, 105 & & $\mathrm{X}$ & Estructuras artesanales/piletas/indeterminado \\
\hline
\end{tabular}

Figura 11: Tabla con los principales testimonios arqueológicos de época altoimperial 


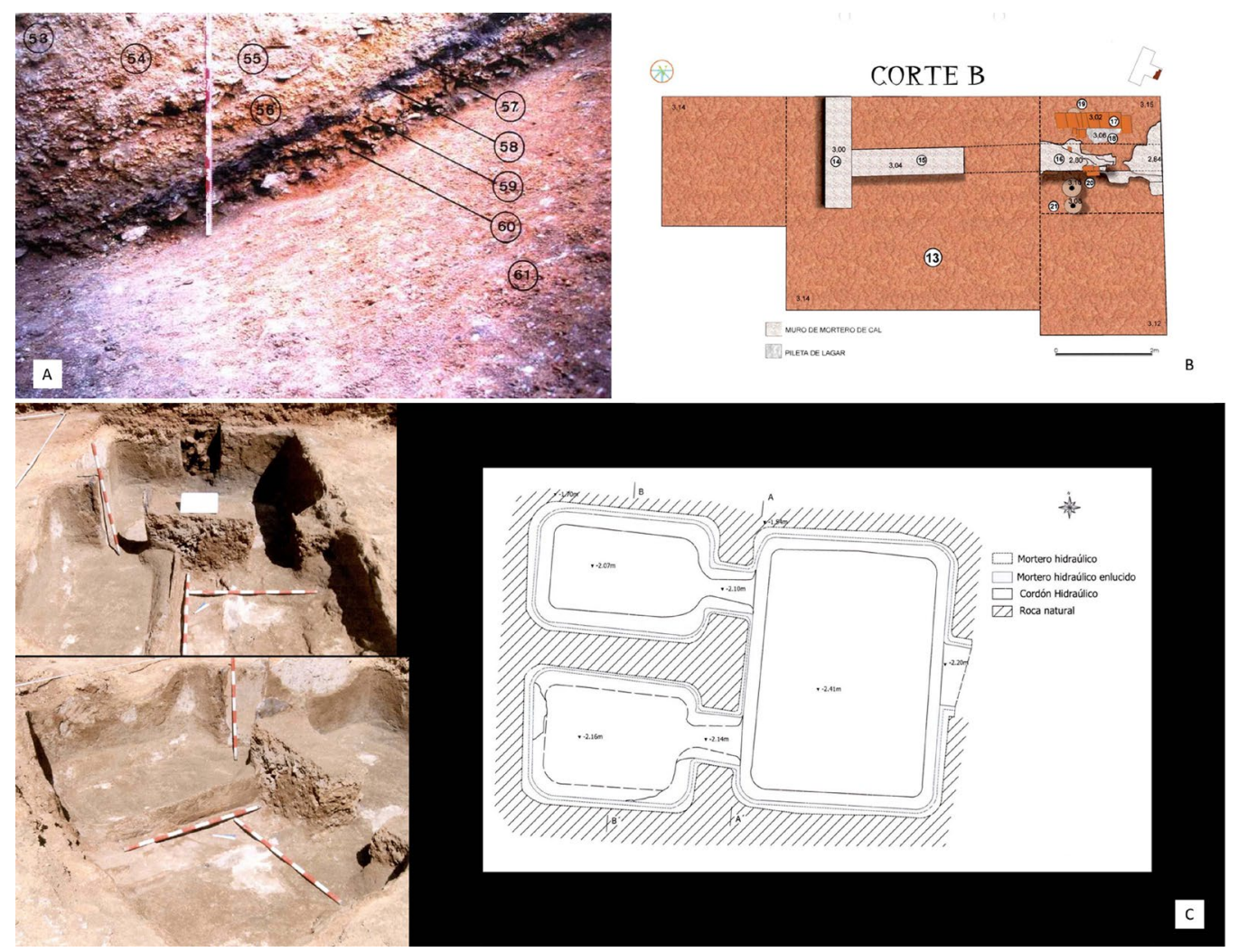

Figura 12: Testimonios arqueológicos de vertidos en la calle Sagasta, 28 (A.- Blanco y Alarcón, 1996: Lám. 8a), área de producción en la calle Chile, 2-4 (B.- Pajuelo, 2001) y piletas de uso artesanal indeterminado de la calle Sagasta (C.- Pineda, 2007: 53 y plano 6)

cerámicos -no publicados- fechados especialmente en época de Claudio (Blanco, 1997). En las proximidades de ambos lugares se han documentado vertidos de similar naturaleza con material cerámico defectuoso y aparentemente sincrónico (altoimperial), como en la calle Soledad, 15 (Blanco, 2009), en la calle Soledad, 30 (Bernal-Casasola et al., 2020c), en la calle Solano, 17-21 (Nota de Prensa de la Delegación Provincial de Cultura de Cádiz) y en la calle Ancha, 29, datos inéditos y pendientes de un estudio de detalle.

Otros datos indirectos de menor entidad pero igualmente reveladores son los correspondientes a varios solares de la calle Gregorio Marañón. La intervención del año 1987 permitió hallar un pequeño horno de fundición de metales de época romana, así como nueve ánforas alineadas posiblemente asociadas a cuatro enterramientos de época púnica (Perdigones y Muñoz, 1991). Un gran vertedero cerámico aparecido en la actuación anterior fue excavado en 1989, junto a estructuras murarias artesanales de época romana, indeterminadas funcionalmente (Blanco, 1991). Recientemente, se ha excavado en el solar contiguo en El Olivillo una interesante secuencia cronológica que avala la existencia en este entorno de un gran vertedero, conformado por ánforas y descargas de la industria pesquero-conservera, denominado el Testaccio haliéutico de Gades (Bernal-Casasola y Vargas, 2019; BernalCasasola et al., 2019). De la última fase proceden varios niveles con hallazgos puntuales de ánforas salazoneras con defectos de cocción (hipercocidas), fechadas entre época augustea y momentos tardo neronianos o primo flavios.

Es interesante en este punto destacar los aspectos morfológicos y dimensiones de este gran vertedero, pues tuvo que ser un verdadero referente geográfico y náutico tanto por sus dimensiones como por su localización a orillas de Eritía y en la embocadura del estrecho interinsular. Sus dimensiones se han estimado utilizando múltiples indicadores (desde la zona excavada a los datos de excavaciones de urgencia realizadas en las inmediaciones -calle Gregorio Marañón 1985 y 1987-, pasando por la cartografía del s. XVIII en la cual se advierte el Testaccio haliéutico gaditano parcialmente desmantelado): con al menos $7 \mathrm{~m}$ de altura -estando cortado en su parte superior en época moderna- pero habiendo podido alcanzar originalmente entre $25 / 30$ $\mathrm{m}$, si tenemos en cuenta los fenómenos de compresión de los vertidos orgánicos (tras la degradación por lixiviación, deshidratación y otros fenómenos análogos), la documentación de muros artificiales con ánforas reutilizadas para crear terrazas artificiales y caminos de acceso al monte y el máximo ángulo de reposo del sedimento alrededor del $30^{\circ}$ máximo (Bernal-Casasola y Vargas, 2019: 278); y con una extensión variable con dos posibilidades de 4415 y $12265 \mathrm{~m}^{2}$, lo cual constituye aproximadamente el $20 \%$ del tamaño del Testaccio de Roma, y da una idea de la importancia de este mons artificial (Bernal-Casasola y Vargas, 2019: 279). Por último, cabe mencionar la existencia de otros vertidos al sur del canal, que aunque situados en la estrecha 
lengua de tierra occidental de la isla grande, denotan que la dinámica ocupacional no se restringió al ámbito suburbial de Gades: al menos dos puntos cercanos, sitos la calle Venezuela, 3, 9 y la calle Pericón de Cádiz, 10, ambos de cronología coetánea (finales del s. I a. C.-s. II d. C.) (Blanco, 1996; 2004; Blanes, 1997, respectivamente) y vinculados con el procesado de las sordes urbis, ambos lugares en fase de estudio actualmente.

Además de lo comentado hasta ahora y a tenor de los datos que proporciona la arqueología preventiva, el suburbio occidental habría albergado otros enclaves productivos y artesanales de diversa naturaleza. Entre ellos destacamos tres ambientes (la plaza de San Antonio, la calle Chile, 2-4 y la calle Sagasta, 105), que permiten traer a colación la importancia del sector agrícola y, quizá, vitivinícola. Por su parte, las estructuras documentadas en la plaza de San Antonio, desde los inicios de su excavación a finales de los años 80 han sido consideradas de dudosa adscripción funcional, ya que nunca se han publicado in extenso. Este conjunto ha sido vinculado tradicionalmente con espacios de uso termal, funerario o indeterminado, atribuciones basadas en algunos pilares hallados en el extremo oriental y por el hallazgo de piletas escalonadas (Expósito, 2007: 106). Otros autores han prestado atención a los materiales muebles documentados, en especial al instrumental pesquero y a los contextos cerámicos, así como a las cisternas (interpretadas como piletas) y a la cercanía de este enclave al posible canal Bahía-Caleta, tomando estos datos como suficientes para interpretar este conjunto como una factoría de salazón (Perdigones, 1990: 3-4; García Vargas, 1998: 187; Lagóstena, 2001: 112), aunque no existe ningún testimonio arqueológico concluyente. La ausencia de indicadores empíricos solo permite afirmar que nos encontramos ante un conjunto estructural bien planificado, con orden simétrico, donde posiblemente se llevarían a cabo actividades que requerían agua en abundancia, pues así lo corroboran los restos arqueológicos relacionados con la captación hídrica (tres cisternas, un pozo y una canalización), así como un posible lugar de almacenamiento de grano (horreum) (análisis en detalle y discusión en Lara, 2019b). Este espacio podría ser relacionado con los restos estructurales documentados en la vecina Alameda Apodaca (López Eliso, 2011), pudiendo localizarse en dicha zona los espacios residenciales de una villa cuya pars rustica se localizaría en la controvertida, desde un punto de vista arqueológico, plaza de San Antonio.

En esta misma línea argumental contamos con los espacios productivos exhumados en la calle Chile, 2-4 (Fig. 12: B), interpretados como parte de un espacio de producción vitivinícola, con la existencia de piletas interpretadas como lagares, construidas en época tardorrepublicana, con modificaciones y ampliaciones hasta el s. II d. C., momento en el cual todo este espacio fue abandonado y convertido en una zona de vertedero (Pajuelo, 2001; Lara, 2019b: 148-150). Probablemente, pudieron haber formado parte de una gran zona fabril que se extendió más allá de la calle San Rafael, como corroboraría la existencia de pavimentos similares recuperados en la calle Benito Pérez Galdós (Blanco, 2007) y en el Hospital Real Militar (Lavado, 1998), área donde se ha documentado un vertido del s. II d. C. que amortiza algunas piletas interconectadas, escalonadas a diversas alturas.

Recordamos en este contexto que durante la construcción de actual Teatro Falla se localizaron restos arqueológicos de diversa índole, posiblemente lagares también que el arquitecto A. Morales de los Ríos describía así «Profundizadas las capas de barro empezaron á encontrarse restos numerosísimos de alfarería romana. Cuellos, asas, fondos, cascos de amphora [...] se conservaban intactas. Se encontraban colocadas en filas y enterradas según la costumbre romana de guardar líquidos. [...] Descubrióse una pequeña alberca sobre un suelo consolidado de piedra partida. La alberca tenía su fondo con vertientes al centro, hacia una especie de cazoleta central, excepto por uno de sus costados en el que se derivaba un canal cuya endeble inclinación correspondía al borde superior de otras dos albercas diferentes en superficie y volumen y colocadas más bajo que la primera en un declive del terreno...Al mismo tiempo las albercas segunda y tercera comunicaban por otro surtido y aprovechando siempre desniveles del terreno» (Ramírez, 1982, 123-125). Es decir, cubetas interconectadas a diversas alturas que inducen a pensar en actividades artesanales que requerían decantación del producto. Todos estos datos son de gran interés, pero están necesitados de un estudio en profundidad de las evidencias aparecidas en la calle Chile y de análisis carpológicos/sedimentológicos que permitan verificar la relación de las mismas con la producción de vino; una idea, por otro lado, nada descabellada si tenemos presente el gran potencial agrícola de estos terrenos, los usos de esta zona de Cádiz en época moderna y la existencia en época romana de ánforas de producción local/regional (Haltern 70, Dr. 28 y tipo urceus), excelentes candidatos para la comercialización ultramarina de estos caldos gaditanos.

Debemos indicar por último que, al otro lado del canal, se localizó en el n. ${ }^{\circ} 105$ de la calle Sagasta (Fig. 12: C) un conjunto estructural compuesto por cinco piletas/contenedores de difícil interpretación (Pineda, 2007). Intercomunidades y a diferente altura (¿para facilitar la decantación?). Esta anómala tipología de las balsas presenta analogías - lejanas - con decantadores oleícolas como los de Los Villaricos (González y Fernández, 2009: 357) o con lacus y con estructuras de decantación como las de El Gallumbar o Torre Águila (Peña, 2010: 128 y 129). Aunque tampoco debemos olvidar su potencial relación con la acuicultura, como ha sido planteado también, tratándose de piletas geminadas para permitir la cría de taxones diferentes o de peces en diverso estadío de crecimiento, muy similares a las aparecidas en la Avda. de Constitución de San Fernando o a las de Gallineras (Bernal-Casasola, 2018).

Por lo tanto, Eritía, a tenor de los datos que hemos expuesto en las páginas precedentes, conforma un 
espacio que no estuvo destinado exclusivamente a las labores haliéuticas como historiográficamente se había considerado, fenómeno que llama poderosamente la atención. Debemos destacar la potencialidad de la isla menor para el desarrollo de las actividades de agricultura, cerealicultura y especialmente la vitinicultura, como han confirmado recientemente los análisis palinológicos realizados en la intervención arqueológica del Colegio Mayor Universitario y, en menor medida, en El Olivillo, donde se aprecia con claridad la existencia de cultivo de vid desde el s. V a. C. con un hiatus entre los ss. II-I a. C. (López Sáez y Pérez, 2019: 415418), aunque lamentablemente hasta la fecha no se han podido documentar zanjas de cultivo, línea interesante para desarrollar en el futuro. Asimismo, sabemos que el paisaje de la isla menor entre los ss. VI/V a. C. estaría conformado por un ambiente forestado, dominado por bosques abiertos de alcornoque y brezos, y en las zonas dunares y arenales costeros prosperarían pinares de pino piñonero (Pinus pinea) y Juniperus: conforme avanza la presencia romana, en el s. II/I a. C., se aprecia una reducción de la cobertura arbustiva de acebuche, si bien las formaciones forestales del entorno de la bahía de Cádiz seguirían dominadas por los alcornoques, viéndose éstos en época altoimperial menos representados a favor del avance de los pinares, con un clima árido en vez de húmedo de la fase anterior. A estas características climáticas y paisajísticas debemos sumarle el grado de antropización, identificado gracias a las herbáceas antrópicas y nitrófilas, que es más elevado según avanzan los períodos con mayor representación de estas hierbas (López Sáez y Pérez, 2019: 415-418).

Además de los cultivos mencionados, desde época púnica se aprecia presión pastoril como demuestra la presencia de herbáceas zoógenas que van en progresión hasta época altoimperial (López Sáez y Pérez, 2019: 415-418). Estos datos cobran mayor entidad gracias al estudio faunístico realizado en El Olivillo y en el Colegio Mayor Universitario, donde están representadas las especies como los caballos y asnos, para la tracción animal, la cabaña vacuna y los ovicápridos, siendo el tipo de ganadería principal la oveja, ya que es la mejor especie representada en la cabaña ganadera y en menor medida el ciervo, la gallina y el conejo. Por su parte, el ganado porcino también está representado, aumentando entre época tardorrepublicana y el Alto Imperio (Riquelme, Vargas y Bernal-Casasola, 2019: 442-455), dato que corrobora la minoritaria presión pastoral conforme avanza el período romano a favor del ganado porcino. Por tanto, las actividades agropecuarias debieron constituir una variable importante en los campos de Eritía, a lo que apuntan con claridad los indicios comentados en estos párrafos, que han de ser ampliados en el futuro con investigaciones arqueozoológicas y arqueobotánicas de mayor entidad.

Finalmente, debemos resaltar otro aspecto o funcionalidad que caracterizaría a esta isla, que es el factor religioso. Como se ha indicado al principio de este trabajo en relación al significado de esta isla, el color rojo y su vinculación constante con la mitología recordarían cotidianamente la trascendencia religiosa que poseía la ciudad desde su fundación. La localización geográfica de este sector de Gades, lugar donde se pone el sol y donde el horizonte marítimo se «une» con el del cielo o el fin del mundo conocido, le confiere un carácter mágico y especial. En esta misma línea argumental tenemos conocimiento por los textos clásicos de que en este extremo se ubicaban al menos dos templos, el de Cronos y el de Venus. Estrabón indicaba «Gades, en el extremo, está el santuario de Crono, junto a la islita; el Heraclion se encuentra al otro lado, al Este, por donde la isla se aproxima más al continente [...]» (Geogr. III, V, 3). Tanto Avieno como Plinio hacen alusión a la localización del templo de Venus en el extremo de la isla menor o Eritía, así como el templo de Crono en el extremo occidental de la isla Mayor o Cotinusa (O.M, Vv. 315-318; Plin. H.N. $3,7)$. A pesar de que la arqueología no ha ofrecido aún datos concluyentes, en una reciente intervención en el castillo de San Sebastián se documentaron algunas estructuras y hallazgos relacionados con un posible espacio sagrado, quizá vinculados al tan citado templo de Crono (Maya et al., 2013). Sin embargo, el templo de Venus aún no ha sido localizado, si bien los restos arqueológicos hallados en las proximidades de la Punta del Nao parecen confirmar el carácter religioso del entorno más próximo (Sáez e Higueras-Milena, 2016). Tradicionalmente, los autores contemporáneos, tomando como referencia a los clásicos, han situado en el castillo de San Sebastián el templo de Crono y en el castillo de Santa Catalina, el de Venus (Corzo, 1982: 150-151; 1983: 76). Otros autores apoyan esta hipótesis tal como lo hizo J. A. Fierro Cubiella (1993). Sin embargo, otros investigadores apuntan la posible ubicación del templo de Venus a modo de faro en el extremo opuesto de la ciudad, en el montículo natural de la isla gaditana cerca de la entrada del brazo de mar de la bahía, en el entorno de la Santa Cueva (Pérez López, 1998).

Sea como fuere, es indiscutible el papel sacro que desempeñó la isla menor de las Gadeira, así como el extremo occidental de Cotinusa, ya que no debemos olvidar que, aunque separados por un estrecho canal, conformaban un mismo espacio, el área suburbana occidental de la ciudad y el acceso al puerto desde el Océano. En este sentido, la configuración topográfica de la isla así como su situación geográfica la convertían en un verdadero referente para la navegación, que es la última vocación de Eritía a tener presente. La costa actúa como un elemento clave en la orientación náutica, y los accidentes geográficos como demarcaciones costeras, como la Punta del Nao, la Torre Tavira por ser el punto más elevado, y la Punta de San Felipe, hitos reconocibles por los marinos y que con los años serían consagrados a las deidades marinas (Gómez Muñoz, 2018). Este carácter dual, como guía para la navegación y como referente religioso, provocó su sacralización, 
una habitual consuetudo desde época griega y fenicia. En este sentido, como bien apunta Gómez, los autores clásicos Avieno y Plinio hacen referencia explícita a la Isla de Venus o Afrodita, apuntando a la tradición sagrada de la isla de Eritía desde sus orígenes (Gómez Muñoz, 2018). Ciertamente, esta faceta religiosa y mística se podría correlacionar con su propio nombre y significado, vinculado con la mitología de Gerión y Hades, debido a su relación con el color rojo proveniente de su etimología y de su origen. No obstante, son aspectos de gran interés que han de ser interpretados con la restante parte del registro arqueológico, mostrando la convivencia en una misma área geográfica de diversas funcionalidades, como es habitual en estos contextos urbanos, territorios que posiblemente dependerían de los templos, ubicados en los lugares más señeros de estas zonas litorales.

\section{CONTINENTIA AEDIFICIA OCCIDENTALIS: EL SUBURBIO OCCIDENTAL DE ERITÍA EN ÉPOCA IMPERIAL}

Como hemos expuesto en el apartado precedente, la etapa tardorrepublicana se configura como un período de transición y experimentación en las áreas territoriales de la Ulterior. Desde época cesariana hasta los momentos augusteos, Roma es protagonista de una sucesión de hechos políticos que crean inestabilidad en las clases políticas (Blázquez, 1988; Novillo, 2010), y que tendrá como resultado final la definitiva configuración de los territorios que conformarán el Imperio.
El área suburbana oriental, como foco primigenio, queda relegado a un segundo lugar, destinándose principalmente a actividades de carácter funerario que alternaban con enclaves residenciales y productivos, como el ilustrado por la villa de los Cuarteles de Varela o el enclave de la calle Juan Ramón Jiménez (Lara, 2019b) o con algunas zonas artesanales, como el taller alfarero de la Avenida de Andalucía - edificio Sindicatos - (Lara, Díaz y Bernal-Casasola, 2015), entre otros ejemplos.

Esta reorganización espacial es especialmente visible en el área suburbana occidental (Fig. 13), fundamentalmente al norte del estrecho interinsular (o canal «Bahía-Caleta»), como evidencian testimonios arqueológicos tales como la construcción de cetariae (Teatro de Andalucía, Cine Cómico, La Caleta, ¿Campo de las Balas?), alfares (calle Solano, 3 y otros conocidos indirectamente en el entorno por sus testares); edificios destinados a la producción de vino o aceite y otras actividades artesanales (¿calle Sagasta, 105?, calle Chile, 2-4, Plaza del Falla y Hospital Real Militar), así como áreas asociadas a posibles explotaciones agropecuarias y vinculada a posibles villae (Alameda), siendo la ganadería y la agricultura de muy reducida visibilidad arqueológica (¿San Antonio? y entorno).

Otras excavaciones han aportado datos de áreas de vertido de residuos sólidos derivados de las actividades productivas, situadas en las zonas altas y más cercanas a ambas orillas del canal y a la playa, generando áreas de relleno. Especialmente relevante en este contexto es el Testaccio haliéutico de Gades, una montaña artificial situada en zona pública (portuaria) que debió

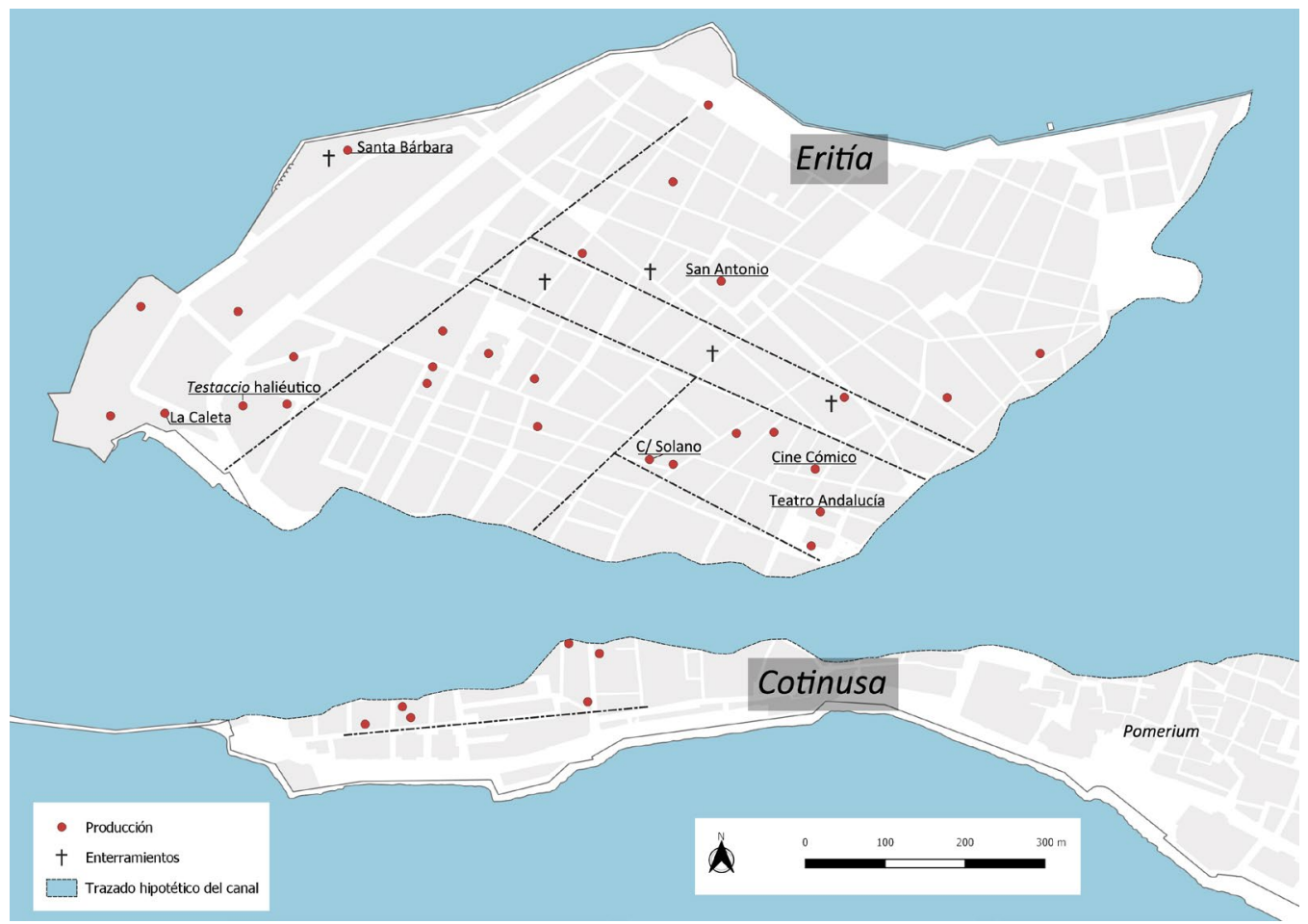

Figura 13: Plano con la propuesta de estructuración interna del territorio del área suburbana occidental (actualizado a partir de Lara, 2019b: fig. 133) 
constituir por ello un hito importante para la topografía de la ciudad y para la navegación (Bernal-Casasola y Vargas, 2019): uno de los vertederos públicos de la ciudad de Gades, que permite indirectamente conocer sus artesanías, especialmente la pesquero-conservera y la producción de tinte púrpura, aunque también aporta información indirecta sobre las tintorerías, la producción textil o la alfarería (Bernal-Casasola, Vargas y Lara, 2019: 509-601 y 658-680), desarrolladas en las inmediaciones.

El análisis espacial de los datos disponibles evidencia la existencia de un claro patrón de asentamiento, con enclaves distribuidos según su naturaleza. Las áreas de procesado piscícola parecen ubicarse en las zonas cercanas a los arroyos, al canal y al mar. Las áreas de vertido se distribuyen en tres ambientes: zonas elevadas, cercanas a los arroyos y próximas al estrecho interinsular. Buena prueba de ellos son los vertidos identificados en las calles Sagasta, Rosario Cepeda y Sacramento, o el reciente hallado en El Olivillo (Testaccio haliéutico), cercano al propio canal y al mar, en el área de La Caleta (Bernal-Casasola y Vargas, 2021). La dinámica estratigráfica de estas intervenciones permite proponer una reconstrucción de la tipología de los vertidos: desechos que se depositan en origen sobre formaciones dunares, que paulatinamente aumentan hasta alcanzar los $3 \mathrm{~m}$ de altura, generando acusados buzamientos derivados de las pendientes que colmatan y elevando la cota de tránsito (se sitúan entre los 10 y 11 m s.n.m.). Junto a las orillas del canal o cerca de la costa, en una dinámica que se detecta constantemente en la arqueología urbana de Cádiz, como resultado de una ciudad insular que debió haber crecido ganando paulatinamente terreno al mar y a su estrecho interinsular.

Este sistema está bien constatado en época romana y cuenta con muchos ejemplos en otras ciudades hispanorromanas. Tal es el caso, por ejemplo, de la ciudad de Tarraco, en el río Francolí, donde se han documentado al menos dos vertederos en su margen izquierda, y donde los humedales fueron desecados paulatinamente mediante la aportación de escombros y residuos, sobre todo de ánforas, aprovechando los declives del terreno (Tarrats, 2000). Otra práctica habitual fue el aprovechamiento de lugares con depresiones en el terreno o con edificaciones abandonadas para destinarlo a áreas de vertidos, como parece ser el caso de la plaza de San Antonio o de las canteras de Santa Bárbara; en el Hospital Real Militar y en la calle Chile, estos hábitos se constatan en el s. II d. C. y son similares a lo que acontece en Cádiz en los ss. XIX y XX con el relleno y progresiva amortización de los aljibes tras su abandono: un buen paralelo lo tenemos en la cisterna del Teatro Andalucía, colmatada progresivamente en momentos avanzados del s. V tras la amortización de la cetaria de la cual dependía (Expósito y Bernal-Casasola, 2007).

Esta práctica tampoco es exclusiva, evidentemente, de Gades, y ha sido documentada en Celsa, Lucentum, Emporiae, Tarraco, Valentia, Carthago Nova y otras ciudades hispanas, donde los espacios que ya dejan de ser usados comienzan a ser receptáculos de vertidos masivos, a partir especialmente del s. II d. C. (Dupré y Remolà, 2002). Este fenómeno es propio de las ciudades que comienzan a sufrir una recesión y regresión urbana (Remolà, 2000), reflejo de la remodelación del escenario que vivirán hacia el patrón de hábitat tardoantiguo, en unas fechas que ya se ha demostrado hace años que se inician en época antoniniana avanzada (Brassous y Quevedo, 2015).

En otras áreas alejadas de estas zonas destinadas a vertederos, se situaban los asentamientos centrados en la producción agropecuaria (villas), como la posiblemente documentada en la Alameda Apodaca (quizá en parte en relación con las estructuras de la plaza de San Antonio). Cronológicamente se aprecia una coetaneidad en el momento de construcción, amortización y abandono de los espacios. Por ejemplo, en la calle Chile y en el Hospital Real, la actividad se inicia a finales del s. I a. C., siendo amortizados en un momento impreciso del s. I d. C., pocas generaciones después (Blanco, 2007: 4). Tras el cese de la actividad productiva y artesanal, los yacimientos son rápidamente cubiertos por dunas producto de la acción eólica, momentos a partir de los cuales no se vuelve a detectar reocupación: este hiatus ocupacional en este sector de la isla, que ha sido también documentado en una reciente intervención en el Colegio Mayor Universitario (Lara y Bernal-Casasola, 2019), corresponde a periodos de actividad cortos, que parecen oscilar entre época de César o Augusto hasta época flavia o primo-antonina.

También destacamos el carácter heterogéneo y polivalente de las áreas de vertidos, donde alternan los residuos de la industria pesquero-conservera con otros de carácter doméstico y de artesanías diversas. Desconocemos por qué tiene lugar esta práctica en dichos ambientes, quizá motivada por la falta de espacio. Esta realidad contrasta con la teoría de un sistema de gestión de residuos bien organizado, a través de un sistema mixto adaptado a la diversidad y heterogeneidad de situaciones (Dupré y Remolà, 2002: 43). El foco de acción abarca la zona central del actual casco histórico de Cádiz (con un radio de $300 \mathrm{~m}$ tomando como epicentro el horno de la calle Solano), que no es el habitual en otras ciudades hispanorromanas en las cuales los residuos se concentran en los extremos del núcleo ciudadano o en ámbito suburbano, como se ha documentado en Mérida (Alba, 1997; Barrientos, 2007) o Baetulo (Padrós, 1998; Comas y Carreras, 2006; Antequera et al., 2010: 180-187), y como es extensible al ámbito mediterráneo en general (Scobie, 1986). En el caso de Gades, es su carácter insular el que justifica y permite entender esta situación, pues en Eritía es donde se concentraban las actividades productivas o los residuos asociados -incluyendo el importante Testaccio haliéutico gaditano-. Al otro lado del canal, en la isla grande, se desarrollaba la vida urbana, dentro del pomerium urbano.

A partir de la lectura y análisis de los datos obtenidos de los testimonios arqueológicos, se puede en la 
actualidad proponer un patrón de asentamiento bien organizado y estructurado en esta zona de Gades (Fig. 13). Parece que el poblamiento en Eritía está regido por un tejido regular muy similar al aplicado en el pomerium urbano, con áreas de ocupación regulares y simétricas en las cuales se insertan los asentamientos. Además, parece que asistimos a una organización administrativa diversa a la existente en el territorio urbano como se ha indicado en muchos otros ejemplos, como en el caso de Iulia Concordia (Annibaletto, 2010). Las cetariae se localizarían en la orilla septentrional del canal, en las cotas más bajas y próximas a éstas los lugares relacionados con la alfarería y otras actividades como las posibles producciones vinícolas, entre otras. En otras áreas alejadas de estos enclaves, parece que se instalaron aquellos asentamientos destinados fundamentalmente a las labores agrícolas y ganaderas insertos o no en el marco económico de las villae. Los alfares ocuparían al menos un foco conocido, en la ladera que desciende hacia la plaza del Falla correspondiente con la calle Solano, calle Benjumeda, y adyacentes, encontrándose estas alfarerías concentradas como sucede en otras ciudades como en la propia Mérida.

De manera aislada se han documentado algunos enterramientos pero sin entidad alguna: la interpretación de los mismos es que se ubicarían en zonas yermas y cercanas a zonas agrícolas como la documentada en el Colegio Mayor Universitario, donde se procedió a deposiciones funerarias puntuales y clandestinas, al alejarse de los espacios cementeriales reglados jurídicamente. Esta dispersión y la escasa representación de los enterramientos documentados hasta la actualidad en esta área suburbial de la ciudad, evidencia claramente que Gades contaba con una única y extensa necrópolis, situada en la parte central de Cotinusa, muy bien conocida arqueológicamente (Arévalo, 2010; Niveau de Villedary y Gómez, 2010).

De este modo, se puede intuir cierto grado de parcelación en el suburbium occidental, que ocuparía una superficie de aproximadamente 4,8 hectáreas al norte del canal, desde su orilla hasta la zona de la actual Alameda Apodaca, aunque es difícil cuantificar exactamente su reborde perimetral al estar completamente amurallado por las fortificaciones de época moderna. El solar de Eritía en época romana pudo haber estado organizado en tres grandes focos de actividad: uno situado en la zona más elevada con las cetariae, las figlinae y otras actividades artesanales, una zona donde se detectan múltiples vertidos aprovechando el desnivel desde la cima de la colina hacia el canal. Un segundo foco en la zona central de la isla, con los enclaves más dispersos entre sí; y un tercer espacio se situaría en la fachada norte de la actual Caleta, en las proximidades del canal. Este patrón corresponde al sistema instaurado por Roma para optimizar los beneficios y la intensiva explotación del territorio conquistado, en este caso litoral, frente a lo que sucede en otros ámbitos de Baetica en los cuales es el hinterland el target productivo (Sáez, Ordóñez y García-Dils, 2005).
Ahora bien, planteamos ciertas cuestiones relativas a estos cambios de los motores productivos de la economía urbana. En primer lugar, ¿cómo justificamos el traslado del núcleo principal de producción de la «isla grande» a la «isla pequeña»? Es decir, de las factorías salazoneras púnicas y tardopúnicas ubicadas entre los ss. V y I a. C. en el entorno de la plaza de Asdrúbal -en la zona media de la isla grande-a su instalación ex novo en la zona suburbial a partir de época augustea. Quizá la respuesta sea múltiple: la orografía, cambios en el patrón de asentamiento y en el modelo de explotación económico. En primer lugar, las nuevas condiciones topográficas del barrio pesquero-conservero periurbano favorecían el resguardo de los vientos de vendaval que tuvieron que azotar la lengua de tierra de la isla mayor, más expuesta a los condicionantes bióticos. También la cercanía al puerto, instalado a ambas orillas del estrecho interinsular a los pies del altozano de la Torre Tavira, maximizaba el trasiego comercial y la compra-venta de salazones, frente a la dificultad que planteaban los acantilados de la «isla grande». En segundo término, la construcción de la Neapolis en el extremo de Cotinusa en época augustea provocó un replanteamiento de la ubicación de los espacios productivos, los cuales fueron concentrados e instalados - preferentemente- al otro lado del estrecho interinsular, en una zona cercana pero peri-urbana. Como pasa en muchas ciudades hispanorromanas, estas nuevas ciudades conservan retazos de su pasado primigenio, pero de manera simbiótica los nuevos patrones de asentamiento generaron cambios estructurales (Bendala, 2005), como parece que sucedió en Gadir/Gades. A estas circunstancias, debemos añadir en tercer lugar el cambio a los nuevos modelos de explotación económica del estado romano, en los cuales el procesado de los recursos piscícolas y demás actividades del sector primario (explotación agropecuaria, vinícola, olearia....) se multiplican exponencialmente. El modelo que desarrolló Augusto se basaba en hacer del territorio un organismo lo más eficaz posible, con deducciones, divisiones agrarias y fundaciones ex novo para un control territorial más eficiente, dando lugar a la materialización de lo que ya inició César, al nacimiento de un nuevo sistema de explotación, las villae (Chic, 1997).

El surgimiento de la explotación privada, y el desarrollo de las villae como modelo preferente de explotación sabemos que encontraron un amplio eco en el archipiélago, con ejemplos como ilustran las villae de los Cuarteles de Varela en Cotinusa (Buzón, 2016) o Gallineras - Cerro de los Mártires (Díaz, Sáez y Sáez, 2016) y Puente Melchor (Bernal-Casasola y Lavado, 2016; Chacón, 2016) en la bahía de Cádiz. Además de ello, sabemos de la intensa roturación con finalidad alfarera y salinera de toda la bahía a partir de época augustea, como definen especialmente en el paisaje el prácticamente centenar de hornos alfareros (BernalCasasola, 2008). Un claro ejemplo de la implantación del sistema fundus/pagus al unir aspectos fiscales, censales y catastrales (Wulff, 1996: 48), factores que 
estructuran el espacio por áreas y hábitats alrededor de un punto central en subordinación administrativa y financiera respecto a él (Rodríguez Neila, 1993-1994). Así parece que sucedió en Gades, y en otras ciudades de Hispania como ilustra magistralmente el barrio artesanal de Carthago Nova en pleno s. I a. C. (Ramallo, Murcia y Vizcaíno, 2010: 238).

A partir de inicios de época tardoantigua el panorama que presenta la ciudad romana es bien distinto, con abandonos generalizados tal y como recordaba Avieno, y con una paulatina invasión funeraria de todos los espacios, como se documenta también en Eritía en la calle Solano, en el Hospital Real Militar y en otros casos (Lara, 2019 b; Bernal-Casasola y Lagóstena, 2010): una dinámica urbana completamente diversa que excede los objetivos planteados en estas páginas.

\section{CONSIDERACIONES FINALES Y PERSPEC- TIVAS: ERITÍA, EL SVBVRBIVM OCCIDENTAL INSULAR DE GADES}

La ciudad es fiel reflejo de la coyuntura política, social y económica y, como ente cambiante, cristaliza y atesora cuantas modificaciones y paulatinas transformaciones se producen en su solar. Los estudios tradicionales y más recientes sobre Gades revelan la notable interrelación de las diversas áreas funcionales de la urbe y de su ager (Bernal-Casasola, 2008; Lara, 2019b), como pasa en otros ambientes urbanos (Abascal y Cebrián, 2010).

Gracias a la exégesis de la documentación procedente de la arqueología preventiva en ámbito urbano, parcial y atomizada como todos sabemos, se propone en estas páginas la identificación de la llamada isla pequeña o Erítía como una nueva área suburbana de Gades, habiendo sido interpretada hasta la fecha como espacio intra moenia. Parece que esta zona tuvo tal carácter periurbano desde época republicana, o incluso antes; sin embargo, su conformación como tal fue desarrollada a partir de inicios de época imperial, como determinan los testimonios arqueológicos, transformándose de manera radical para convertirse en el principal centro productivo de la capital del Conventus Gaditanus. Mayoritariamente centrado en las actividades de producción, con cetariae y figlinae subordinadas a ellas, también se incluyen en estas páginas indicios de la posible producción viti-vinícola y de otras artesanías cuya hermenéutica no es sencilla a través del análisis único de sus estructuras de producción. Un ambiente productivo, el de la isla menor, necesario para una ciudad clave en el comercio de redistribución internacional, situada estratégicamente junto al cauce del Baetis y dominando el océano Atlántico (Chic, 1997), con uno de los sistemas portuarios más relevantes de todo el Mediterráneo Occidental (Bermejo, Marfil y Campos, 2018).

A partir de Augusto los cambios comentados perceptibles en el registro arqueológico reflejan una intensa reorganización en pro de la implantación de un patrón de asentamiento propio de época romana, tendente a la organización racional de este sector desde el punto de vista económico, administrativo y de la propiedad (Guzmán Armario, 2015: 42-49).

Aunque en estas páginas hacemos una propuesta de extensión, los límites no están aún bien definidos. Según M. Frayn (1993) el espacio suburbano es el situado desde las murallas de la urbe hasta $5 \mathrm{~km}$ de lejanía respecto a las mismas: de ahí en adelante todo pertenecería al ager. Otros autores como S. Panciera, plantean el límite de la urbe y de su área periurbana a partir de la llamada passus mille, es decir, la primera milla existente desde los límites del pomerium hacia su territorio (1999) ${ }^{3}$. En el caso que nos ocupa, las condiciones topográficas particulares del enclave por su insularidad lo convierten en un caso especial, puesto que la ciudad y su espacio periurbano comprenden en total no más de 3,9 km lineales. Definir los límites y las áreas funcionales del área suburbana de la ciudad de Gades no es tarea fácil, más aún cuando se trata de una ciudad costera, portuaria e insular cuyas características topográficas son muy variables y dinámicas, como pasa en otras zonas mediterráneas (Santoro y Sassi, 2010: 35).

Con todo, quedan pendientes múltiples cuestiones relacionadas con la configuración definitiva de este sector y con su integración e interactuación con el resto de la ciudad. Quizás uno de los más relevantes sea la exigüidad de testimonios vinculados con las zonas portuarias. Han sido muchas las propuestas sobre la localización del enclave portuario: la zona de La Caleta, en las proximidades de la calle Sagasta, 104, donde se excavó el muelle sur del canal, según su excavador, recortado parcialmente en la roca y recrecido con mampostería y relleno de arcilla roja (Corzo, 1982: 148); próximo a este último enclave se documentaron algunos muros de mampostería que han sido interpretados como posibles diques (García Sánchez, 2008) y zonas de posible atraque en la plaza de Abastos (Blanco y Belizón, 2008). En fechas más recientes se había planteado la existencia de dos puertos, uno abierto al mar y otro hacia la bahía, al estar parcialmente cegado el canal (Bernal-Casasola, 2012). Este planteamiento cambia radicalmente si tenemos en cuenta las últimas propuestas geoarqueológicas, comentadas en estas

\footnotetext{
3. La primera milla es considerada gracias a las aportaciones de las fuentes literarias y las fuentes arqueológicas, el lugar donde se hallaría el área suburbana de las ciudades romanas, puesto que en los textos clásicos se hace alusión a lugares sagrados donde se celebraban festividades relacionadas con la fertilidad de los campos. La primera cita la documentamos con Catón en el s. II a. C., Tito Livio, Cicerón en sus Filipicas, y Ovidio para época republicana. En época imperial, hacen mención a ello Marcial, Séneca (advierte que comienza en el cuarto miliario), Plinio y Apuleyo. Interesante la propuesta de S. Panciera, puesto que la festividad llamada Terminales, en la cual se veneraba a Júpiter Término, se ha establecido en Roma entre los miliarios IV y VI (Panciera, 1999).
} 


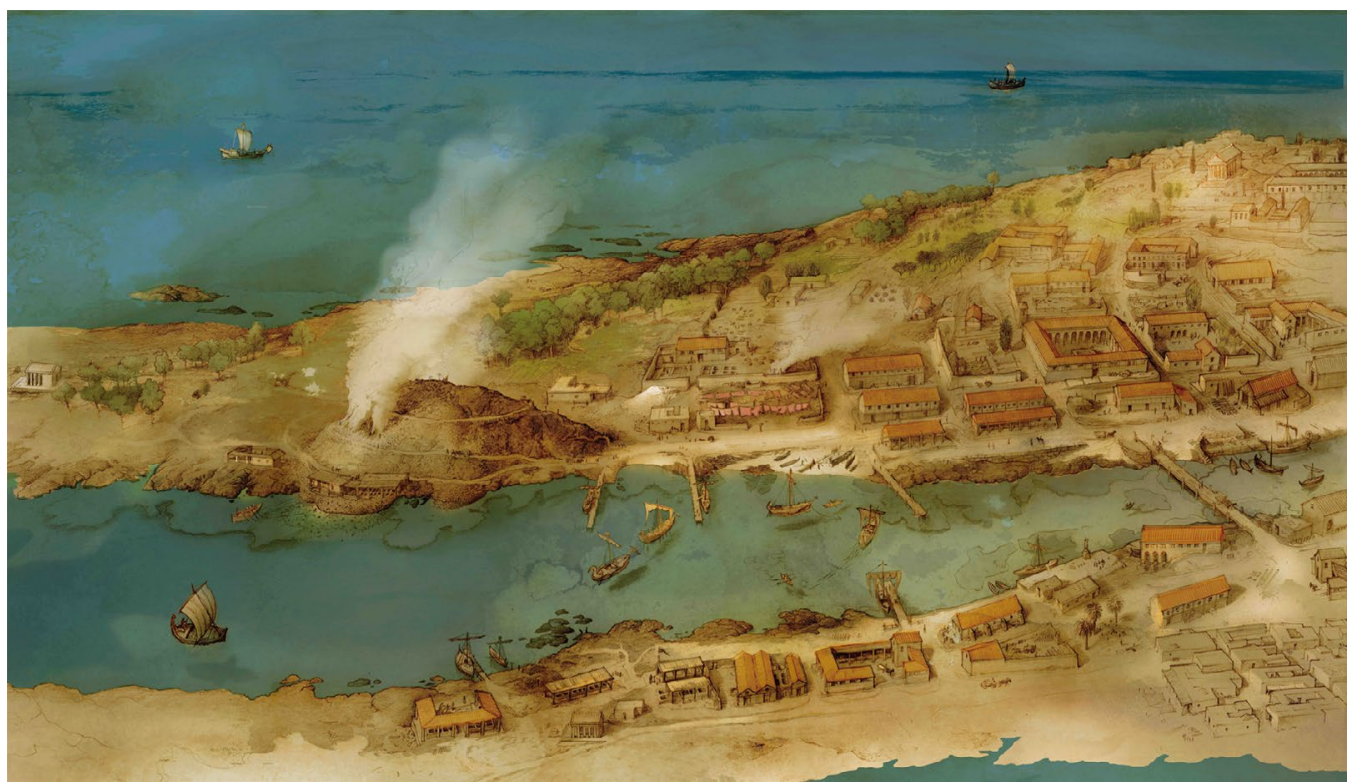

Figura 14: Recreación del estrecho interinsular de Gades con una intensa actividad portuaria y comercial, y con la combinación en Eritía de las actividades artesanales (cetariae, figlinae, officinae tinctoriae...) y las agropecuarias, en edificios en fundi aislados y en villae, con espacios de carácter sacro (Bernal-Casasola y Vargas, 2019: 281, fig. 33)

páginas, que han verificado la completa apertura del estrecho interinsular a lo largo de toda la Antigüedad, lo que debió provocar la existencia de instalaciones portuarias estables y de cierta entidad combinadas con atraques menores a lo largo de todo su trazado, y a ambas orillas, como se plantea en las ilustraciones científicas más recientes (Fig. 14). En este contexto se sitúa el reciente hallazgo de la Cueva del Pájaro Azul, aparentemente de fechas un poco anteriores -s. III a. C. circa $^{4}$-. Sea como fuere, debieron existir numerosos embarcaderos en la zona sur, este y norte de la isla menor, como pasa en muchos ambientes suburbanos mediterráneos (Santoro, Sassi y Hoti, 2010).

Otro tema pendiente y que concierne a este espacio es la localización de santuarios y templos, cuestión comentada en las páginas precedentes, y que ha preocupado a cuantos se han acercado a la problemática de Gadir/Gades. Por las fuentes clásicas sabemos que existían al menos dos templos, el de Venus y el de Cronos, habiéndose reflexionado recientemente sobre la problemática de este último gracias a indicios aparecidos en el Castillo de San Sebastián (Maya et al., 2013). Posiblemente en Eritía existieron templos

\footnotetext{
4. En 2020 se documentó durante el desarrollo de una rehabilitación de un edificio en la calle San Juan, 37, una gran estructura compuesta por bloques de sillares tallados de biocalcarenita. Junto a esta estructura, de 1'80 $\mathrm{m}$ de altura y 5,60 m de longitud, se ha podido documentar una escalera que daría acceso al agua y una rampa para varar los barcos, cuya cronología es de época fenicio-púnica. Fuente: https://www.diariodecadiz. es/ocio/Aparece-mitico-puerto-Gadir_0_1476452938.html Actualmente estas estructuras se encuentran en fase de estudio por diversos investigadores de la Universidad de Cádiz junto a los excavadores y dueños de la propiedad.
}

y territorios sagrados que dependían de ellos y con total seguridad, dadas las características topográficas y la situación geográfica de la isla menor, ésta fue un importante referente costero y sagrado en la Antigüedad (Gómez Muñoz, 2018).

También será necesario en los próximos años reflexionar sobre la configuración de la zona suburbana oriental y la simbiosis entre las áreas de necrópolis y las áreas productivas, interacción que sabemos existió como se ha comentado de manera epidérmica. Un análisis topográfico similar al aquí realizado podrá aportar datos importantes sobre el conocimiento del suburbium oriental de Gades instalado sobre Cotinusa, cuya articulación interna parece mucho más compleja y polifuncional de lo inicialmente planteado.

Del mismo modo, será interesante precisar con detalle la cronología de las actuaciones preventivas citadas, de las cuales únicamente se han realizado avances preliminares hasta ahora. En esta misma línea, se deberán abordar estudios de materiales en detalle con el objeto de intentar realizar atribuciones funcionales, ya que es la única manera de intentar contar con más datos empíricos aparte de los expuestos en estas páginas 5 poder con ello, a medio plazo, abandonar la recurrente $\mathrm{y}$ «desgraciadamente» aún necesaria cita a «informes» $\mathrm{y}$ «memorias» inéditos.

Por último, otra línea de investigación a continuar en un futuro es el estudio paleotopográfico de detalle de las orillas del canal Bahía-Caleta y la paleolínea de costa en el litoral sur de la isla y en los entornos

5. Actualmente, los contextos materiales de algunas de estas intervenciones están siendo objeto de estudio desde 2020 en el marco del proyecto CEIJ-006 ya citado. 
adyacentes, actualmente no planteada más allá de su aparición sobre la cota $+5 / 6$ m s.n.m. sobre los planos de principios de siglo. Ello permitirá estar muy atento a la interfaz marítimo-terrestre, la zona donde probablemente se podrán producir más hallazgos en los próximos años, especialmente en el reborde meridional de Eritía.

\section{REFERENCIAS}

Abad Casal, L. y Corzo Sánchez, R. (2017). Gadir/Gades/ Cádiz. Muchas novedades pendientes de una interpretación global. En M. M. Ros Sala (Ed.). Phicaria, V Encuentros Internacionales del Mediterráneo. Conviviendo con la Arqueología: las capitales de las grandes potencias mediterráneas en la Antigüedad. Una mirada alternativa (pp. 88-103). Mazarrón: Universidad Popular de Mazarrón.

Abascal, J. M. y Cebrián, R. (2010). El paisaje suburbano de Segóbriga. En D. Vaquerizo (Ed.). Las áreas suburbanas en la ciudad histórica. Topografia, usos, función (pp. 289308). Monografías de Arqueología Cordobesa, 18. Córdoba: Universidad de Córdoba.

Alarcón Castellano, F. J. (1996). Informe preliminar de la Intervención arqueológica de urgencia en el solar $n^{\circ} 27$ de la calle san José (Cádiz). Documento inédito depositado en la Delegación Provincial de Cultura de Cádiz.

Alba Calzado, M. (1997). La actividad industrial emeritense en época romana. Foto, 8, 6-7.

Annibaletto, M. (2010). Per una topografía del limite: riflessioni sul suburbio di Iulia Concordia. En D. Vaquerizo (Ed.). Las áreas suburbanas en la ciudad histórica. Topografía, usos, función (pp. 67-78). Monografías de Arqueología Cordobesa, 18. Córdoba: Universidad de Córdoba.

Antequera, F., Rigo, A., Padrós, P. y Vázquez, D. (2010). El suburbium occidental de Baetulo. En D. Vaquerizo (Ed.). Las áreas suburbanas en la ciudad histórica. Topografía, usos, función (pp. 173-210). Monografías de Arqueología Cordobesa, 18. Córdoba: Universidad de Córdoba.

Antequera Devesa, F., Vázquez Álvarez, D. y Rigo Jovells, A. (2011). Desenvolupament urbà i industrial extramurs de Baetulo: ocupació republicana, centre productor amfòric $\mathrm{i}$ necròpolis altimperials. Tribuna d'Arqueologia, 16, 265-294.

Arévalo González, A. (2010). Gades. En D. Vaquerizo (Ed.). Necrópolis urbanas en Baetica (pp. 142-170). Documenta, 15. Tarragona: Universidad de Sevilla - Instituto Catalán de Arqueología Clásica.

Arévalo González, A. (2011-2012). Continuidad e impronta púnica en la necrópolis de Gades. Evidencias monetales. Cuadernos de Prehistoria y Arqueología de la Universidad Autónoma de Madrid, 37-38, 525-538. DOI: https://doi. org/10.15366/cupauam2012.38.027

Arévalo González, A. (2016). Moneda para el más allá. Uso y significado de la moneda en las necrópolis tardopúnicas y romanas de Ebusus, Gades y Malaca. Cádiz - Málaga: Universidad de Cádiz - Universidad de Málaga.
Arteaga, O., Kölling, A., Kölling, M., Roos, A. M., Schulz, H. y Schulz, H. D. (2001). El puerto de Gadir. Investigación geoarqueológica en el casco antiguo de Cádiz. Revista Atlántica-Mediterránea de Prehistoria y Arqueología Social, 4,345-415. DOI: https://doi.org/10.25267/Rev_atl-mediterr prehist_arqueol_soc.2001.v4.13

Arteaga, O. y Roos, A. M. (2002). El puerto-fenicio púnico de Gadir. Una nueva visión desde la geoarqueología urbana de Cádiz. Spal, 11, 21-39. DOI: https://doi.org/10.12795/ spal.2002.i11.02

Arteaga, O. y Schulz, H.D. (2008). Geoarqueología y proceso histórico en la bahía de Cádiz. Revista AtlánticaMediterránea de Prehistoria y Arqueología Social, 10, 7-20. Recuperado de: https://revistas.uca.es/index.php/rampas/ article/view/2257/2043

Avieno. Ora Maritima. Traducción de José Calderón Felices. (Ed. 2001). Barcelona: Editorial Gredos.

Ballabriga, A. (1986). Le soleil et le Tartare. L'image mythique du monde en Grèce archaique. Paris: École des hautes études en sciences sociales.

Barrientos Vera, T. (2007). Una figlina emeritense extramuros del siglo I d.C. y la ocupación funeraria del espacio en época bajoimperial y andalusí. Mérida, Excavaciones Arqueológicas, 10 (2004), 371-407.

Belvedere, O. (1997). Politica urbanística e ideología nella Sicilia della prima età imperiale. En L. Quilici y S. Quilici (Eds.). Architettetura e pianificazione urbana nell'Italia antica (pp.17-24). Roma: L'Erma di Bretschneider.

Bendala Galán, M. (2000-2001). Estructura urbana y modelos urbanísticos en la Hispania antigua. Zephyrus, 53-54, 413-432.

Bendala Galán, M. (2005). Urbanismo y romanización en el territorio andaluz: aportaciones a un debate en curso. Mainake, XVII, 9-32.

Bermejo Meléndez, J., Marfil Vázquez, F. y Campos Carrasco, J. M. (2018). De Gades a Hispalis: dos puertos atlánticos en la conformación de la provincia Baetica. Onoba, 6, 97-112. DOI: https://doi.org/10.33776/onoba.v0i6.3404

Bernal-Casasola, D. (2008). Gades y su bahía en la Antigüedad. Reflexiones geoarqueológicas y asignaturas pendientes. Revista Atlántica-Mediterránea de Prehistoria y Arqueología Social, 10, 267-308. DOI: https://doi.org/10.25267/Rev_atlmediterr_prehist_arqueol_soc.2008.v10.08

Bernal-Casasola, D. (2012). El puerto romano de Gades: novedades arqueológicas. En S. Keay (Ed.). Rome, Portus and the Mediterranean (pp. 225-244). Archaeological Monographs of The British School at Rome, 21. London: British School at Rome.

Bernal-Casasola, D. (2018): Arqueología de la acuicultura en Hispania. Problemas y reflexiones. En D. Bernal-Casasola y R. Jiménez-Camino (Eds.). Las cetariae de Ivlia Tradvcta. Resultados de las excavaciones arqueológicas en la calle San Nicolás de Algeciras (2001-2006) (pp. 375-396). Cádiz: Editorial Universidad de Cádiz. 
Bernal-Casasola, D., Alarcón, F., Cantillo, J. J., Marlasca, R., Vargas, J. M. y Lara, M. (2014). La púrpura en la Gades altoimperial. Descargas heterogéneas de artesanías en la calle Sagasta 28. En J. J. Cantillo, D. Bernal-Casasola y J. Ramos (Eds.). Moluscos y púrpura en contextos atlántico-mediterráneos. Nuevos datos y reflexiones en clave de proceso histórico (pp. 299-318). Cádiz: Editorial Universidad de Cádiz.

Bernal-Casasola, D., Arévalo, A., Muñoz, A., Expósito, J.A., Díaz, J. J., Lagóstena, J.... y Bustamante, M. (2013). Las termas y el suburbium marítimo de Baelo Claudia. Avance de un reciente descubrimiento. Revista Onoba, Arqueología e Historia, 1, 115-152. DOI: https://doi.org/10.33776/onoba. v0i1.1376

Bernal-Casasola, D., Díaz Rodríguez, J. J. y Lavado Florido, M. L. (2008). Un taller alfarero en el barrio industrial urbano de Gades. A propósito del horno cerámico de la C/ Solano 3 (Cádiz). Spal, 17, 317-322. DOI: https://doi.org/10.12795/ spal.2008.i17.13

Bernal-Casasola, D. y Lagóstena, J. (2010): Muriendo en Gades en la Antigüedad Tardía. En A. M. Niveau de Villedary y V. Gómez (Eds.). La necrópolis de Gadir-Gades. Homenaje a F. J. Sibón Olano (pp. 407-444). Cádiz: Universidad de Cádiz.

Bernal-Casasola, D. y Lara Medina, M. (2012). Desenterrando a Gades. Hitos de la Arqueología Preventiva. Mirando al futuro. En J. Beltrán y O. Rodríguez (Eds.). Hispaniae Urbes. Investigaciones arqueológicas en ciudades históricas (pp. 423-473). Sevilla: Universidad de Sevilla.

Bernal-Casasola, D. y Lavado Florido, M. L. (2016): Puente Melchor (Puerto Real, Cádiz). En R. Hidalgo Prieto (Coord.). Las villas romanas de la Bética, vol. II (pp. 78-93). Sevilla: Universidad de Sevilla.

Bernal-Casasola, D., Salomon, F., Díaz Rodríguez, J. J., Lara Medina, M. y Rixhon, G. (2020a). Un cambio de paradigma paleotopográfico en Gadir-Gades. Geoarqueología de profundidad en su estrecho interinsular (Canal Bahía-Caleta). Archivo Español de Arqueología, 93, 125-147. DOI: https:// doi.org/10.1007/s11457-020-09258-w

Bernal-Casasola, D., Salomon, F., Díaz Rodríguez, J. J., Lara Medina, M., Rixhon, G., Morales-Mateos, J., y Vidal Matutano, P. (2020b). Deeper than expected: the finding of a remarkable ancient anchorage at Gadir/Gades and an exceptional sedimentary archive (Cadiz, southern Spain). Journal Maritime Archaeology, 15(2), 165-183.

Bernal-Casasola, D., Díaz Rodríguez, J. J., Oviedo Callealta, J., Lavado Florido, M. L. y Lara Medina, M. (2020c). Morteros, jarras y ánforas de una nueva figlina en Gades: los contextos cerámicos de la Calle Soledad. Boletín de la SECAH, 11, 46-51.

Bernal-Casasola, D. y Vargas Girón, J. M. (2019). El testaccio haliéutico de Gades. En D. Bernal-Casasola, J. M. Vargas y M. Lara (Eds.). 7 metros de la Historia de Cádiz. Arqueología en El Olivillo y en El Colegio Mayor Universitario (pp.237-327). Cádiz: Editorial Universidad de Cádiz.

Bernal-Casasola, D. y Vargas Girón, J. M. (2021): El Testaccio haliéutico de Gades. Un yacimiento con 3000 años de Historia bajo El Olivillo. En A. J. Gullón, L. Padrón y C. Pérez-Reverte (Eds.). La Caleta. Entre la tierra y el mar. Un estudio diacrónico de uso (pp. 121-138). Textos Universitarios, 46. Sevilla: Aconcagua Libros.

Bernal-Casasola, D., Vargas Girón, J. M., Gómez, M. S., Lara Medina, M. y Retamosa Gámez, J. A. (2019). De la cronología del Testaccio haliéutico de Gades. Un singular hallazgo de ámbito portuario en las excavaciones de El Olivillo. En J. Coll Conesa (Coord.). Opera fictiles: estudios transversales sobre cerámicas antiguas de la Península Ibérica, vol. 2 (pp. 395-416). Valencia: La Ergástula.

Bernal-Casasola, D., Vargas, J. M. y Lara, M. (Eds.). (2019). 7 metros de la Historia de Cádiz. Arqueología en El Olivillo $y$ en El Colegio Mayor Universitario. Cádiz: Editorial Universidad de Cádiz.

Blanco Jiménez, F. J. (1991). Excavaciones de urgencia en un solar de la Calle Gregorio Marañón. Cádiz. Anuario Arqueológico de Andalucía 1989, Tomo III (pp. 78-81). Sevilla: Junta de Andalucía.

Blanco Jiménez, F. J. (1996). Informe arqueológico preliminar de un solar en C/ Venezuela, $n^{\circ} 3$. Documento inédito depositado en la Delegación Provincial de Cultura de Cádiz.

Blanco Jiménez, F. J. (1997). Informe preliminar de los resultados obtenidos en la I.A.U. realizada en la Calle Rosario Cepeda $n^{\circ}$ 2, 4, 6 y 8 (Cádiz). Documento inédito depositado en la Delegación Provincial de Cultura de Cádiz.

Blanco Jiménez, F. J. (2002). Comentario de los resultados arqueológicos obtenidos del sondeo realizado en la $C /$ Marqués del Real Tesoro, 13 (Cádiz). Documento inédito depositado en la Delegación Provincial de Cultura de Cádiz.

Blanco Jiménez, F. J. (2004). Informe arqueológico de los resultados obtenidos en la calle Venezuela, 9 (Barrio de la Viña, Cádiz). Documento inédito depositado en la Delegación Provincial de Cultura de Cádiz.

Blanco Jiménez, F. J. (2007) Informe arqueológico del control de movimientos de tierra efectuado en el solar C/ Benito Pérez Galdós esquina con la C/ Chile (Cádiz). Documento inédito depositado en la Delegación Provincial de Cultura de Cádiz.

Blanco Jiménez, F. J. (2009). Informe Memoria final de la C/ Soledad, 15. Documento inédito depositado en la Delegación Provincial de Cultura de Cádiz.

Blanco Jiménez, F. J. y Alarcón Castellano, F. J. (1996). Informe arqueológico: avance de los resultados obtenidos en la I.A.U. realizada en la calle Sagasta $n^{\circ} 28$ (Cádiz). Documento inédito depositado en la Delegación de Cultura de Cádiz.

Blanco, F. J. y Belizón, R. (2008). Intervención arqueológica en la rehabilitación de la Plaza de Abastos de Cádiz. Avance de los trabajos realizados. Documento inédito depositado en la Delegación Provincial de Cultura de Cádiz.

Blanes Delgado, C. (1997). Informe intervención arqueológica de urgencia C/ Pericón de Cádiz, $n^{\circ}$ 10, Cádiz. Documento inédito depositado en la Delegación Provincial de Cultura de Cádiz.

Blázquez Martínez, J. M. (1988). Hispania en época julioclaudia. En J. Arce y J. González (Eds.). Estudios sobre la 
Tabula Siarensis (Madrid 6-10 de Mayo de 1986) (pp. 201232). Anejos de Archivo Español de Arqueología, 9. Madrid: CSIC.

Brassous, L. y Quevedo, A. (2015): Urbanisme civique en temps de crise. Les espaces publics d'Hispanie et de l'Occident romain entre le II ${ }^{e}$ et le IV siècle. Collection de la Casa de Velázquez, 149. Madrid: Casa de Velázquez.

Burkert, W. (1977). Le mythe de Géryon: Perspectives préhistoriques et tradition rituelle. En B. Gentili y G. Paioni (Eds.). Il mito greco. Atti del Convegno internazionale (Urbino 7-12 maggio 1973) (pp. 273-284) Roma: Edizioni dell'Ateneo \& Bizzarri.

Buzón Alarcón, M. (2011). Reflexiones acerca del suburbio en la ciudad romana. Romula, 10, 7-42. Recuperado de: https://www.upo.es/revistas/index.php/romula/article/ view/226/221

Buzón Alarcón, M. (2016). Antiguos Cuarteles de Varela (Cádiz). En R. Hidalgo Prieto (Coord.). Las villas romanas de la Bética, vol. II (pp. 39-46). Sevilla: Universidad de Sevilla.

Calderón Quijano, J. A. (1976). Las defensas del Golfo de Cádiz en la Edad Moderna. Sevilla: CSIC - Escuela de Estudios Hispano-Americanos.

Chacón Mohedano, C. (2016): Barrio Jarana - Puente Melchor (Puerto Real, Cádiz). En R. Hidalgo Prieto (Coord.). Las villas romanas de la Bética, vol. II (pp. 73-77). Sevilla: Universidad de Sevilla.

Chic García, G. (1997). La transformación de los sistemas de convivencia: hacia la formación de las urbes en el Sur de Hispania. Gades, 22, 221-240.

Chic García, G. (2017). Perspectivas económicas de la Bética de Augusto. Gerión, 35, 839-861. DOI: https://doi. org/10.5209/GERI.56176

Cobos, L., Muñoz, A. y Perdigones, L. (1997). Intervención arqueológica en el solar del antiguo Teatro Andalucía de Cádiz: la factoría de salazones y la representación gráfica del faro de Gades. Boletín del Museo de Cádiz, 7 (19951996), 115-132.

Comas, M. y Carreras, C. (2006). Les àmfores de la Laietània: estat de la qüestió. En A. López Mullor y X. Aquilué Abadías (Coords.). La producció i el comerç de les àmfores de la «Provincia Hispania Tarraconensis». Homenatge a Ricard Pascual i Guasch (pp. 177-188). Monografies, 8. Barcelona: Museu d'Arqueologia de Catalunya.

Córdoba Alonso, I. (2005). Memoria preliminar actividad arqueológica preventiva en la Calle Ceballos $n^{\circ} 1-5 \mathrm{E} / \mathrm{A} C /$ Navas $n^{\circ} 13$ (Cádiz). Documento inédito depositado en la Delegación de Cultura de la Provincia de Cádiz.

Córdoba Alonso, I. y Ruiz Mata, D. (2005). El asentamiento fenicio arcaico de la Calle Cánovas del Castillo (Cádiz). Un análisis preliminar. Archivo Español de Arqueología, $X X X V$, 1269-1322.

Corzo Sánchez, R. (1982). Sobre la topografía de Cádiz en la Edad Media. Estudios de Historia y Arqueología medievales, $2,147-154$.
Corzo Sánchez, R. (1983). Panorama arqueológico de la ciudad de Cádiz. En Primeras Jornadas de Arqueología en las ciudades actuales (pp.75-82). Zaragoza: Ayuntamiento de Zaragoza, Delegación de Patrimonio Histórico-Artístico.

Corzo Sánchez, R. (1989). Los sacrificios infantiles en Cádiz. Cuadernos de Prehistoria y Arqueología Castellonenses, 14, 239-246.

Corzo, R. (1992). Topografía y ritual en la necrópolis de Cádiz. Spal, 1, 263-292. DOI: https://doi.org/10.12795/ spal.1992.11.13

Díaz, J. J., Bernal-Casasola, D., Martelo, M., Portillo, J. L., Oviedo, J. y Lorenzo, L. (2021): Indicios de un nuevo taller de ánforas tardopúnicas en Gadir/Gades a partir de las evidencias documentadas en la c/ Sacramento 38. Boletín de la SECAH, 12, 23-29.

Díaz, J. J., Sáez Romero, A. M. y Sáez Espligares, A. (2016): Gallineras - Cerro de los Mártires (San Fernando, Cádiz). En R. Hidalgo Prieto (Coord.). Las villas romanas de la Bética, vol. II (pp. 94-106). Sevilla: Universidad de Sevilla.

Domínguez-Bella, S. (2008). Geología en el entorno de la ciudad de Cádiz. Revista Atlántica-Mediterránea de Prehistoria y Arqueología Social, 10, 117-130. Recuperado de: https://revistas.uca.es/index.php/rampas/article/ view/1361/1187

Dupré Raventós, X. y Remolà Vallverdú, J. A. (2002). A propósito de los residuos urbanos en Hispania. Romula, 1, 39-56. Recuperado de: https://www.upo.es/revistas/index. php/romula/article/view/128/122

Esteban, J. M. (2020). Nuestra querida piedra ostionera. Un estudio de este material. Su procedencia, características y sus formas de empleo en el Urbanismo y la Arquitectura de la zona gaditana. Cádiz: Edición financiada por el autor.

Estrabón. Geografía. Libros I - III. Traducción a cargo de J. Gómez Espelosín. Introducción y notas de M. J. Meana y F. Piñero. Barcelona: Gredos.

Expósito Álvarez, J. A. (2007). Las factorías de salazón de Gades (ss. II a. C.-VI d.C.). Estudio arqueológico y estado de la cuestión. (Trabajo de investigación de Tercer Ciclo). Universidad de Cádiz. Cádiz.

Expósito Álvarez, J. A. (2021). Los talleres salazoneros de La Caleta. Del Club Náutico al Castillo de Santa Catalina. En A. J. Gullón, L. Padrón y C. Pérez-Reverte (Eds.). La Caleta. Entre la tierra y el mar. Un estudio diacrónico de uso (pp. 105-119). Textos Universitarios, 46. Sevilla: Aconcagua Libros.

Expósito Álvarez, J. A. y Bernal-Casasola, D. (2007): Ánforas orientales en el Extremo Occidente. Las importaciones de LR 1 en el sur de Hispania. En M. Bonifay y J.-Ch. Tréglia (Eds.). LRCW 2. Late Roman Coarse Wares, Cooking Wares and Amphorae in the Mediterranean. Archaeology and Archaeometry (pp. 119-132). British Archaeological Reports, 1662 (I). Oxford: BAR Publishing.

Fernández Camacho, P. (2012). La imagen de Cádiz en los textos griegos y latinos: un análisis filológico-literario. 
(Tesis doctoral). Universidad de Cádiz. Cádiz. Recuperado de: http://hdl.handle.net/10498/17238

Fernández Díaz, A., Bernal-Casasola, D., Castillo Alcántara, G. y Vargas Girón, J. M. (2019). Los restos pictóricos del «Testaccio» haliéutico de Gades (El Olivillo, Cádiz). Primera muestra del primer estilo pompeyano en la Bética. Spal, 28(2), 203-234. DOI: http://dx.doi.org/10.12795/spal.2019. i28.20

Fernández Vega, P. (1994). Las áreas periurbanas de las ciudades altoimperiales romanas. Usos del suelo y zonas residenciales. Hispania Antiqua, 18, 141-158.

Ferreiro López, M. (2008). Cádiz en el tiempo de César y los Balbo. La ordenación territorial en la Bahía de Cádiz a finales de la República romana. Revista Atlántica-Mediterránea de Prehistoria y Arqueología Social, 10, 309-324. DOI: https://doi.org/10.25267/Rev_atl-mediterr_prehist_arqueol_ soc.2008.v10.09

Fierro Cubiella, J. A. (1993). Historia de la ciudad de Cádiz. Cádiz.

Frayn, M. (1993). Markets and Fairs in Roman Italy. Oxford: Oxford University Press.

García Sánchez, M. (2008). Intervención arqueológica preventiva en C/Sagasta, 96-98. Documento inédito depositado en la Delegación Provincial de Cultura de Cádiz.

García Vargas, E. (1998). La producción de ánforas en la Bahía de Cádiz en época romana (ss.II a.C.- IV d.C.). Écija: Gráficas Sol.

García Vargas, E., Almeida, R. R. de, González Cesteros, H. y Sáez Romero, A. M. (Eds.). (2019). The Ovoid Amphorae in the Central and Western Mediterranean. Between the Last two Centuries of the Republic and the Early Days of the Roman Empire. Roman and Late Antique Mediterranean Pottery, 13. Oxford: Archaeopress. DOI: https://doi. org/10.2307/j.ctvpmw4m6

Garriguet, J. A. (2010). El anfiteatro de Colonia Patricia-Cor$d u b a$ en el marco de la ideología imperial. En D. Vaquerizo y J. F. Murillo (Eds.). El anfiteatro romano de Córdoba y su entorno urbano. Análisis arqueológico (ss. I-XIII d.C.) (pp. 466-480). Monografías de Arqueología Cordobesa, 19. Córdoba: Universidad de Córdoba.

Gavala y Laborde, J. (1924). Mapa geológico de la provincia de Cádiz. Madrid: Instituto Geológico y Minero de España.

Gavala y Laborde, J. (1973). El origen de las islas gaditanas. Cádiz: Instituto de Estudios Gaditanos de la Diputación Provincial.

Gener, J., Navarro, M. A. y Pajuelo, J. M. (2010). Memoria final de la intervención arqueológica puntual en el solar del antiguo Teatro Cómico. Cádiz (2006-2010). Documento inédito depositado en la Delegación Provincial de Cultura de Cádiz.

Gener, J. M., Navarro, M. A., Pajuelo, J. M., Torres, M. y López, E. (2014). Arquitectura y urbanismo de la Gadir fenicia. El yacimiento del Teatro Cómico de Cádiz. En M. Botto (Ed.). Los fenicios en la Bahía de Cádiz. Nuevas investigaciones (pp. 14-50). Collezione di Studi Fenici, 46. Pisa-Roma: Fabrizio Serra.

Gómez Muñoz, S. (2018). La isla sagrada de Venus Marina. Un antiguo referente sacro para la navegación en la Bahía de Cádiz. Revista Atlántica-Mediterránea de Prehistoria y Arqueología Social, 20, 129-146.

González Fernández, R. y Fernández Matallana, F. (2009). La uilla de Los Villaricos (Mula, Murcia). Un ejemplo de asentamiento rural romano. En J. M. Noguera Celdrán (Ed.). Poblamiento rural romano en el sureste de Hispania. 15 años después (pp. 347-375). Murcia: Editum.

Goodman, P. J. (2007). The roman city and its periphery. From Rome to Gaul. Cambridge: Routledge.

Gracia Prieto, F. J. (2019). Geología y geomorfolgía en el extremo suroeste de Erytheia. En D. Bernal-Casasola, J. M. Vargas y M. Lara (Eds.). 7 metros de la Historia de Cádiz. Arqueología en El Olivillo y en El Colegio Mayor Universitario (pp. 121-135). Cádiz: Editorial Universidad de Cádiz.

Guzmán Armario, F. J. (2015). La Bética en la geopolítica de Augusto. En C. Márquez y E. Melchor (Coords.). Augusto y la Bética. Aspectos históricos y arqueológicos (pp. 41-57). Córdoba: Universidad de Córdoba.

Herrero Lapaz, N. (2005). Intervención arqueológica de urgencia en el solar de Plaza de las Viudas, $n^{\circ} 13-15$. Documento inédito depositado en la Delegación Provincial de Cultura de Cádiz.

Jiménez Cisneros, M. J. (1971). Historia de Cádiz en la Antigüedad. Cádiz: Instituto de Estudios Gaditanos.

Jolivet, V. (Ed.). (2009). Suburbium II: il suburbio di Roma dalla fine dell'eta monarchica alla nascita del sistema delle ville (V-II secolo a.C.). Roma: École Française de Roma.

Jurado Fresnadillo, G. (2001). Informe de la actividad de urgencia y del seguimiento de los movimientos de tierras realizados en el solar $n^{\circ} 24$ de la calle Vea Murgía de Cádiz. Documento inédito depositado en la Delegación Provincial de Cultura de Cádiz.

Lagóstena, L. (2001). La producción de salsas y conservas de pescado en la Hispania romana. Colecció Instrumenta, 11. Barcelona: Universidad de Barcelona.

Lara Medina, M. (2018a). Gades y la problemática del canal Bahía-Caleta. Novedades desde la arqueología. En J. Moreno-Andrés, M. Bolado-Penagos, F. Sánchez-García, I. Jerez-Cepa, M. Simón, M. Pérez-Miguel,... y J. I. GonzálezGordillo (Eds.). I Congreso de Jóvenes Investigadores del Mar (pp. 417-419). Cádiz: Universidad de Cádiz.

Lara Medina, M. (2018b). Entre tradición y transformación. Un primer acercamiento a los sistemas de almacenaje de agua en Gadir/Gades. Complutum, 29(1), 95-114. DOI: https://doi. org/10.5209/CMPL.62397

Lara Medina, M. (2018c). Sobre el abastecimiento, la distribución y la evacuación hídrica en Gades. Zephyrus, LXXXI, 141-163. DOI: https://doi.org/10.14201/ zephyrus201881141163 
Lara Medina, M. (2019a). Arqueología en la ciudad: un escenario complejo de difícil interpretación. En M. Bustamante-Álvarez y E. H. Sánchez López (Eds.). Arqueología Romana en la Península Ibérica (pp. 198-199). Granada: Universidad de Granada.

Lara Medina, M. (2019b). Urbs Iulia Gaditana. Arqueología y urbanismo de la ciudad romana de Cádiz al descubierto. Cádiz: Universidad de Cádiz.

Lara Medina, M. (s. f.). De las canteras. Primeras evidencias de los sistemas de explotación en Gades. En IX Encuentro de Arqueología del Suroeste Peninsular (Tróia-Setúbal, 2016).

Lara Medina, M. y Bernal-Casasola, D. (2019). De las excavaciones en el Colegio Mayor Universitario de Cádiz. En D. Bernal-Casasola, J. M. Vargas y M. Lara (Eds.). 7 metros de la Historia de Cádiz. Arqueología en El Olivillo y en El Colegio Mayor Universitario (pp.31-69). Cádiz: Editorial Universidad de Cádiz.

Lara Medina, M., Díaz, J. J. y Bernal-Casasola, D. (2015): Excavando en los archivos. Novedades sobre la alfarería romana en Gades a partir de la documentación arqueológica del solar de la Avenida Andalucía 8-10. Boletín de la Sociedad de Estudios de la Cerámica Antigua en Hispania, 6, 28-35.

Lavado Florido, M. L. (1998). Informe preliminar de la intervención arqueológica en el antiguo Hospital Real Militar. Documento inédito depositado en la Delegación Provincial de Cultura de Cádiz.

Lavado Florido, M. L. (2002). Resultado final del control arqueológico de un solar en la calle Vea Murgía esquina calle Cervantes de Cádiz. Documento inédito depositado en la Delegación Provincial de Cultura de Cádiz.

López Eliso, J. M. (2011). Memoria final actividad arqueológica preventiva, obras de pavimentación de la Alameda Apodaca. Fase II. Documento inédito depositado en la Delegación Provincial de Cultura de Cádiz.

López Sáez, J. A. y Pérez Díaz, S. (2019). Palinología. El clima y la vegetación en Erytheia: el contexto de El Olivillo y del Colegio Mayor Universitario. En D. Bernal-Casasola, J. M. Vargas y M. Lara (Eds.). 7 metros de la Historia de Cádiz. Arqueología en El Olivillo y en El Colegio Mayor (pp. 415-418). Cádiz: Editorial Universidad de Cádiz.

Macías López, M. M. (2009). Contribución de la Antropología y la Paleopatología a la interpretación en la Arqueología Funeraria. Un ejemplo en la necrópolis gaditana del siglo II a.C. Anales de arqueología cordobesa, 20, 67-94.

Manúel-Vez, M. P. y García Vargas, M. (1992). Características edafológicas de algunos suelos agrícolas de «La Almoraima». Almoraima: revista de estudios campogibraltareños, 8, 91-100. Recuperado de: http://institutoecg.es/ wp-content/uploads/2019/02/Almoraima8-Articulo8.pdf

Maya Torcelly, R, Jurado Fresnadillo, G, Gener Basallote, J. M., López Rosendo, E y Torres Ortiz, M. (2013). Nuevos datos sobre el Kronion de Gadir: Resultados de la intervención arqueológica en el Castillo de San Sebastián (Cádiz). En N. Medina Rosales (Ed.). VII Encuentro de arqueología del suroeste peninsular (Aroche-Serpa, 29 de noviembre al 1 de diciembre de 2013) (pp. 429-451). Huelva: Ayuntamiento de Aroche.

Muñoz Vicente, A., Frutos Reyes, G. de y Berriatua Hernández, N. (1996). Contribución a los orígenes y difusión comercial de la industria pesquera y conservera gaditana a través de las recientes aportaciones de las factorías de salazones de la Bahía de Cádiz. Spal, 5, 487-508. DOI: https:// doi.org/10.12795/spal.1996.i5.07

Niveau de Villedary y Mariñas, A. M. (2007). Continuidad púnica en la Gades republicana. La producción vascular del horno. Spal, 16, 195-224. DOI: https://doi.org/10.12795/ spal.2007.i16.10

Niveau de Villedary y Mariñas, A. M. (2009). Ofrendas, banquetes y libaciones. El ritual funerario en la necrópolis púnica de Cádiz. Spal Monografías, XII. Sevilla: Secretariado de Publicaciones, Universidad de Sevilla - Servicio de Publicaciones, Universidad de Cádiz.

Niveau de Villedary y Mariñas, A. M. (2015). La estructuración del espacio urbano y productivo de Gadir durante la Fase Urbana Clásica: cambios y perduraciones. Complutum, 26(1), 225-242. DOI: https://doi.org/10.5209/rev_CMPL.2015.v26. n1.49351

Niveau de Villedary, A. M. y Gómez, V. (2010). Captación y uso del agua en contextos funerarios y rituales. Estructuras hidráulicas en la necrópolis de Cádiz (siglos III a.C.-I d.C.). En L. G. Lagóstena, J. L. Cañizar y L. Pons (Eds.). Aqvam Perdvcendam Cvravit. Captación, uso y administración del agua en las ciudades de la Bética y el Occidente Romano (pp. 511-532). Cádiz: Seminario Agustín de Horozco.

Niveau de Villedary, A. M. y Gómez, V. (Eds.). (2010). La necrópolis de Gadir-Gades. Homenaje a F. J. Sibón Olano. Cádiz: Editorial Universidad de Cádiz.

Novillo López, M. A. (2010). La propretura cesariana en la Hispania Ulterior: La II guerra lusitana. Gerión, 28(1), 207-221.

Ortega Alba, F. (1975-1976). Tres estudios agrobiológicos dedicados a Andalucía Occidental. Cuadernos Geológicos, 5-6, 281-283.

Padrós, P. (1998). Can Peixau. Un centre productor d'àmfores al territorium de Baetulo. En $2^{\circ}$ Col-loqui Internacional d'Arqueologia Romana: El vi a l'antiguitat. Economia, producció I comerç al Mediterrani occidental (pp. 185-192). Monografies Badalonines, 14. Badalona: Museu de Badalona.

Pajuelo, J. M. (2001). Seguimiento arqueológico del vaciado del solar, 2, 4 y $4 \mathrm{D}$ de la calle Chile y $n^{\circ} 5$ de la calle San Rafael. Documento inédito depositado en la Delegación Provincial de Cultura de Cádiz.

Panciera, S. (1999). Dove finisce la città? En S. Quilici (Ed.). La forma della città e del territorio. Esperienze metodologiche risultati a confronto (pp. 9-15). Roma: L'Erma di Bretschneider.

Pascual Sánchez, M. A. (2019). Pavimentos con inclusiones conchíferas y teseladas en El Olivillo. En D. Bernal-Casasola, J. M. Vargas y M. Lara (Eds.). 7 metros de la Historia de Cádiz. Arqueología en El Olivillo y en El Colegio Mayor 
Universitario (pp. 649-652). Cádiz: Editorial Universidad de Cádiz.

Peña Cervantes, Y. (2010). Torcularia: la producción de vino $y$ aceite en Hispania: catálogo de yacimientos analizados en cedé. Tarragona: Institut Català d'Arqueologia Clàssica.

Perdigones Moreno, L. (1988). Excavaciones arqueológicas en la Plaza de San Antonio de Cádiz. Documento inédito depositado en la Delegación Provincial de Cultura.

Perdigones Moreno, L. (1989). Diario de Campo de la excavación en el Club Náutico La Caleta. Documento inédito depositado en la Delegación Provincial de Cultura de Cádiz.

Perdigones Moreno, L. (1990). Arqueología de urgencia en Cádiz durante 1989. Anuario Arqueológico de Andalucía, 1989(1), 10-13.

Perdigones Moreno, L. y Muñoz Vicente, A. (1991). Intervenciones de urgencia en las necrópolis y zonas industriales de la ciudad de Cádiz. Anuario Arqueológico de Andalucía, 1991(1), 9-12.

Pérez López. I. (1998). Los santuarios de la Baetica en la Antigüedad. Cádiz: Universidad de Cádiz.

Pineda Reina, P. (2001). Informe de intervención arqueológica a realizar en el solar del Pabellón de deportes del centro histórico (Cádiz). Cádiz: Documento inédito depositado en la Delegación Provincial de Cultura de Cádiz.

Pineda Reina, P. (2007). Memoria final de la intervención I.A.PR. C/ Sagasta $n^{\circ}$ 105. Cádiz: Documento inédito depositado en la Delegación Provincial de Cultura.

Pineda Reina, P. (2012). APP Aparcamiento Subterráneo de Santa Bárbara. Memoria final de la actuación. Documento inédito depositado en la Delegación Provincial de Cultura de Cádiz.

Plinio. Historia Natural. Traducción a cargo de de E. del Barrio Sanz (Ed. 1998). Barcelona: Biblioteca Clásica Gredos.

Pomponio Mela. Corografía. Traducción y notas a cargo de C Guzmán Arias (Ed. 1989). Murcia: Universidad de Murcia.

Ponce Cordones, F. (1985). Consideraciones en torno a la ubicación del Cádiz fenicio. Anales de la Universidad de Cádiz, 2, 99-121.

Quilici, L. (1974). La campagna romana come suburbio di Roma. La Parola del Passato, 29, 410-438.

Quintero Atauri, P. (1917a). Excavaciones en Punta de la Vaca y en Puertas de Tierra (ciudad de Cádiz). Memorias de los trabajos realizados en 1916. Memorias de la Junta Superior de Excavaciones y Antigüedades, 5. Madrid: Junta Superior de Excavaciones y Antigüedades.

Quintero Atauri, P. (1917b). Cádiz primitivo. Primeros pobladores: hallazgos arqueológicos. Cádiz: Obra de Vulgarización Histórica.

Quintero Atauri, P. (1928). Compendio de la Historia de Cádiz. Cádiz: Ayuntamiento de Cádiz.
Ramallo, S. F., Murcia, A. J. y Vizcaíno J. (2010). Carthago Nova y su espacio suburbano. Dinámicas de ocupación en la periferia de la urbs. En D. Vaquerizo (Ed.). Las áreas suburbanas en la ciudad histórica. Topografía, usos, función, Monografías de arqueología cordobesa, 18. (pp. 211-254). Córdoba: Universidad de Córdoba.

Ramírez Delgado, J. R. (1982). Los primitivos núcleos de asentamiento en la ciudad de Cádiz. Cádiz: Ayuntamiento de Cádiz.

Remolà, J. A. (2000). Sobre la interpretación arqueológica de los vertederos. En X. Dupré y J. A. Remolà (Eds.). Sordes Urbis. La eliminación de los residuos en la ciudad romana (pp. 107-121). Roma: L'Erma di Bretschneider.

Riquelme Cantal, J. A., Vargas Girón, J. M. y Bernal-Casasola, D. (2019). Restos faunísticos en El Olivillo. Entre el consumo alimenticio y la tracción animal. En D. BernalCasasola, J. M. Vargas y M. Lara (Eds.). 7 metros de la Historia de Cádiz. Arqueología en El Olivillo y en El Colegio Mayor Universitario (pp. 442-455). Cádiz: Eitorial Universidad de Cádiz.

Rodríguez Neila, J. F. (1980). El municipio romano de Gades. Cádiz: Instituto de Estudios Gaditanos, Diputación Provincial.

Rodríguez Neila, J. F. (1993-1994). Ciudad y territorio en la provincia romana de la Bética. Florentia Iliberritana: Revista de estudio de antigüedad clásica, 4-5, 445-484. Recuperado de: https://core.ac.uk/download/pdf/230542183.pdf

Ruiz Nieto-Guerrero, M.A. y Jiménez Mata, J. J. (2019), Historia urbana de Cádiz II. Permanencia y transformación a partir de 1800. Cádiz: Lampreave.

Sáez Fernández, P., Ordóñez Agulla, S. y García-Dils, S. (2005). El urbanismo de la Colonia Avgvsta Firma Astigi: nuevas perspectivas. Mainake, XVII, 89-112. Recuperado de: https://hdl.handle.net/11441/72372

Sáez Romero, A. M. y Belizón Aragón, R. (2014). Excavaciones en la calle Hércules, 12 de Cádiz. Avance de resultados y primeras propuestas acerca de la posible necrópolis fenicia insular de Gadir. En M. Botto (Ed.). Los Fenicios en la bahía de Cádiz. Nuevas investigaciones (pp. 181-201). Collezione di Studi fenici, 46. Pisa - Roma: CNR Edizioni.

Sáez Romero, A. M. e Higueras-Milena Castellano, A. (2016). Nuevas investigaciones arqueológicas subacuáticas en el área de la Caleta (Cádiz, España). Estudio de las evidencias de época púnica (siglos VI-III a.C.). Lucentum, XXXV, 9-41. DOI: https://doi.org/10.14198/LVCENTVM2016.35.01

Salomon, F., Bernal-Casasola, D., Díaz, J. J., Lara, M., Domínguez-Bella, S., Ertlen, D.,... y Rixhon, G. (2020). High resolution late Holocene sedimentary cores record the long history of the city of Cádiz (Southern Spain). Journal Scientific Drilling, 27, 35-47. DOI: https://doi.org/10.5194/ sd-27-35-2020

Sánchez Aragón, M. J. (2003). Memoria final Parking Club de Tenis. Documento inédito depositado en la Delegación Provincial de Cultura de Cádiz. 
Santoro, S. y Sassi, B. (2010). Fra terra, mare, colline e lagune: le aree suburbane di Dyrrachium (Durrës, Albania). En D. Vaquerizo (Ed.). Las áreas suburbanas en la ciudad histórica. Topografía, usos, función (pp. 35-51). Córdoba: Universidad de Córdoba.

Santoro, S., Sassi, B. y Hoti, A. (2010). Una nuova immagine dell'urbanistica di Epidamnos-Dyrrachium dagli scavi e dalle ricerche del Dipartamento di Archeologia e della Missione Archeologica Italiana a Durrës. En J. L. Lamboley y M. P. Castiglione (Eds.). L'lllyrie méridionale et l'Épire dans l'Antiquité (pp. 299-324). Grenoble: De Boccard.

Scobie, A. (1986). Slums, sanitations and mortaly in the roman world. Klio, 68(2), 399-433. DOI: https://doi. org/10.1524/klio.1986.68.68.399

Sibón Olano, F. J. (2003). Informe arqueológico preliminar del solar de la calle Ancha número 29 (Cádiz). Documento inédito depositado en la Delegación Provincial de Cultura de Cádiz.
Tarrats, F. (2000). Tárraco, topografía urbana y arqueología de los vertederos. En X. Dupré y J. A. Remolà (Eds.). Sordes Urbis. La eliminación de los residuos en la ciudad romana (pp. 129-137). Roma: L'Erma di Bretschneider.

Tsiolis, V. G. (1997). Las restricciones de la producción tegularia en la lex vrsonensis. Studia Historica. Historia Antigua, $15,119-136$.

Vaquerizo, D. (Ed.). (2010). Las áreas suburbanas en la ciudad histórica. Topografía, usos, función. Monografías de Arqueología Cordobesa, 18. Córdoba: Universidad de Córdoba.

Wulff, F. (1996). La acción colonizadora de Augusto en la Bética. En E. Ortiz de Urbina y J. Santos Yanguas (Eds.). Revisiones de Historia Antigua II. Teoría y práctica del ordenamiento municipal en Hispania (pp. 41-52). Anejos de Veleia. Series Acta, 3, Vitoria: Servicio Editorial de la Universidad del País Vasco. 